\title{
Studies of aerosol at a coastal site using two aerosol mass spectrometry instruments and identification of biogenic particle types
}

M. Dall'Osto ${ }^{1}$, R. M. Harrison ${ }^{1}$, H. Furutani ${ }^{2}$, K. A. Prather ${ }^{2}$, H. Coe $^{3}$, and J. D. Allan ${ }^{3}$

${ }^{1}$ Division of Environmental Health and Risk Management, School of Geography, Earth and Environmental Sciences, University of Birmingham, Edgbaston, Birmingham B15 2TT, UK

${ }^{2}$ Department of Chemistry and Biochemistry, Scripps Institution of Oceanography, University of California, San Diego, La Jolla, CA 92093-0314, USA

${ }^{3}$ School of Earth, Atmospheric and Environmental Sciences (SEAES) University of Manchester, PO Box 88, Manchester M60 1QD, UK

Received: 25 May 2005 - Accepted: 23 August 2005 - Published: 27 October 2005

Correspondence to: R. M. Harrison (r.m.harrison@ bham.ac.uk)

(C) 2005 Author(s). This work is licensed under a Creative Commons License.
Studies of aerosol using two aerosol mass spectrometers

M. Dall'Osto et al.

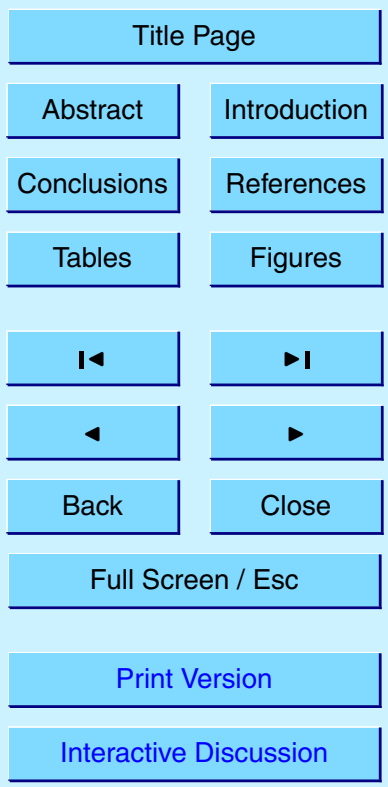




\section{Abstract}

During August 2004 an Aerosol Time-of-Flight Mass Spectrometer (TSI ATOFMS Model 3800-100) and an Aerodyne Aerosol Mass Spectrometer (AMS) were deployed at Mace Head during the NAMBLEX campaign. Single particle data (size, positive and

5 negative mass spectra) from the ATOFMS were imported into ART $2 a$, a neural network algorithm, which assigns individual particles to clusters on the basis of their mass spectral similarities. Results are very consistent with previous time consuming manual classifications (Dall'Osto et al., 2004). Three broad classes were found: sea-salt, dust and carbon-containing particles, with a number of sub-classes within each. The 10 Aerodyne (AMS) instrument was also used during NAMBLEX, providing online, real time measurements of the mass of non-refractory components of aerosol particles as function of their size.

The ATOFMS detected a type of particle not identified in our earlier analysis, with a strong signal at $\mathrm{m} / \mathrm{z} 24$, likely due to magnesium. This type of particle was detected during the same periods as pure unreacted sea salt particles and is thought to be biogenic, originating from the sea surface. AMS data are consistent with this interpretation, showing an additional organic peak in the corresponding size range at times when the Mg-rich particles are detected. The work shows the ATOFMS and AMS to be largely complementary, and to provide a powerful instrumental combination in studies of atmospheric chemistry.

\section{Introduction}

During August and September 2002 the North Atlantic Marine Boundary Layer Experiment (NAMBLEX) took place at Mace Head. The aims of the campaign were to study the oxidation processes, atmospheric chemistry and composition of a number of species primarily in the marine boundary layer. The NAMBLEX experiment is described more fully in Heard et al. (2005). As part of this campaign, two commercially available
ACPD

5, 10799-10838, 2005

Studies of aerosol using two aerosol mass spectrometers

M. Dall'Osto et al.

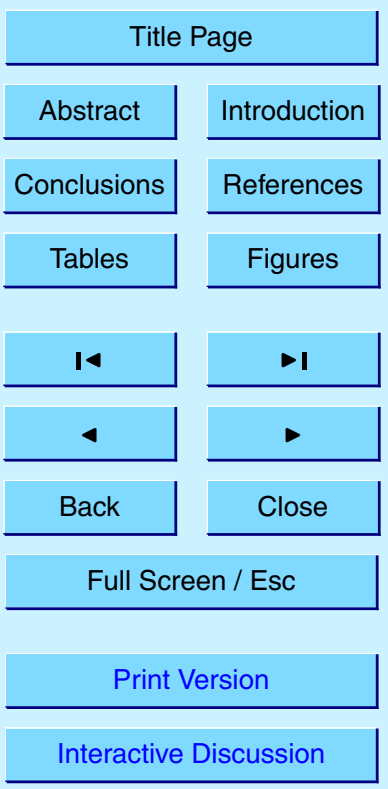

EGU 
particle mass spectrometers Aerosol Mass Spectrometer (AMS-Aerodyne Research, Inc.) and Aerosol Time-of-Flight Mass Spectrometer (ATOFMS, model 3800; TSI Inc.) were deployed.

The ATOFMS provides information on a polydisperse aerosol, acquiring precise 5 aerodynamic diameter $( \pm 1 \%)$ and individual particle positive and negative mass spectral data in real time (Gard et al., 1997; Dall'Osto et al., 2004). The AMS provides online, real time measurements of the mass of non-refractory components of aerosol particles as function of their size (Jayne et al., 2000; Allan et al., 2003a, b; Jimenez et al., 2003). The purpose of this study was to run the two different particle mass spec10 trometers at a remote marine site, and to compare their results. To our knowledge, this is the first study in which the two most widespread commercially available instruments (not prototypes) are compared.

The generally employed method of collecting size-fractionated airborne particles relies on using multistage impactors prior their chemical analysis (McMurry, 2000). However, these methods do not provide any information on the extent of internal or external chemical mixing of the aerosols sampled and furthermore they suffer from a very poor time resolution. The advent of techniques of particle mass spectrometry offers great insights into the source apportionment and atmospheric chemistry of aerosols (Prather et al., 1994; Johnston and Wexler, 1995; Suess and Prather, 1999).

The global mass emission of sea-salt particles is more than 20 times the combined emissions of organics, black carbon, sulphate, nitrate and ammonium in the atmosphere (Raes et al., 2000). Marine aerosol therefore contributes significantly to the global aerosol load and consequently it is important to understand its physical and chemical properties. Moreover, the role of organic compounds in the remote marine aerosol remains uncertain, mainly because of the lack of quantitative measurements of their size-dependent composition.

Recently, O'Dowd et al. (2004) found that during plankton blooms, organic material arising from the sea surface microlayer and generated during bubble bursting contributes $63 \%$ to the submicrometre aerosol mass (about $45 \%$ is water-insoluble and

ACPD

$5,10799-10838,2005$

\section{Studies of aerosol using two aerosol mass spectrometers}

M. Dall'Osto et al.

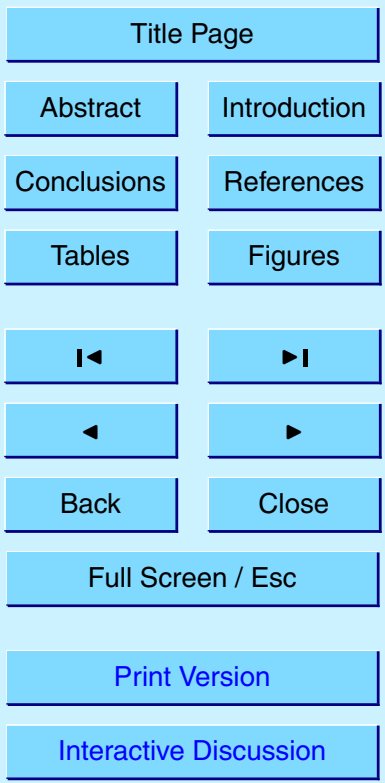

EGU 
about $18 \%$ water-soluble). The report of these types of particles has created great interest in the scientific community. The main reason is the fact that size-dependent chemical composition is considered a critical parameter in defining aerosol properties pertinent to radiative effects. Specifically the large organic content of submicron marine 5 aerosol will greatly alter the cloud nucleating properties of the particles and hence affect the cloud droplet number in marine stratiform clouds (Novakov and Penner, 1993; Kleefeld et al., 2002; O'Dowd et al., 2004).

In order to better understand the speciation of organic marine aerosol, improved aerosol chemical instrumentation is required. In this study we present detailed infor10 mation on aerosol sampled at Mace Head with state-of-the-art instrumentation showing how the combined use of two different aerosol mass spectrometers can enhance knowledge of ambient aerosols.

This paper however has a multiple aim intending to present how:

- TSI ATOFMS (TSI Model 3800) data are for the first time successfully imported into YAADA (Yet Another ATOFMS Data Analyzer), a software toolkit to analyse single particle mass spectral data collected with ATOFMS.

- Single particles with similar mass spectra are classified with an artificial intelligence algorithm (ART-2a), showing similar results to previous manual classification (Dall'Osto et al., 2004).

- A unique, probably biogenic type of particle is also found at Mace Head.

- The complementary nature of ATOFMS and AMS instruments is demonstrated by describing this unique type of particle, thought to be of biogenic origin.

\section{Experimental}

The Mace Head research station is located on the west coast of Ireland $\left(53^{\circ} 19^{\prime} \mathrm{N}\right.$,

$9^{\circ} 54^{\prime} \mathrm{W}$ ) at close to sea level on a peninsula, which is surrounded by coastline and
ACPD

5, 10799-10838, 2005

Studies of aerosol using two aerosol mass spectrometers

M. Dall'Osto et al.

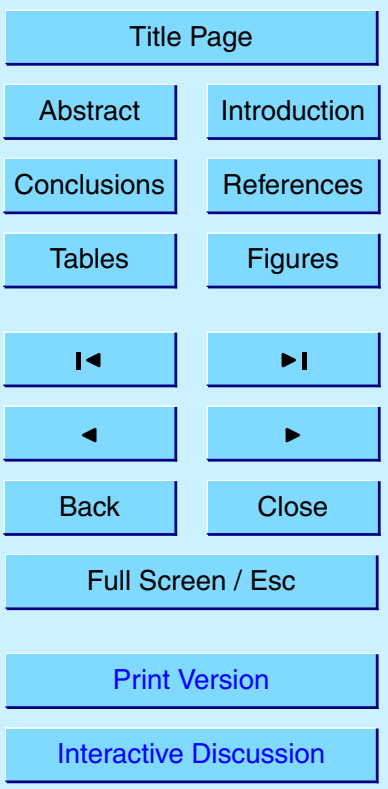

EGU 
tidal areas except for a small sector between $20^{\circ}$ and $40^{\circ}$. The nominal clean sector lies between $180^{\circ}$ and $300^{\circ}$ (Jennings et al., 1997). Further information can be found in Heard et al. (2005).

The Aerosol Mass Spectrometer (AMS) sampled throughout the whole month of 5 August 2002 during NAMBLEX. However, due to instrument failure, no data were available between 13-19 August 2002. The Aerosol Time-of-Flight Mass Spectrometer (ATOFMS) was operated almost continuously at Mace Head Atmospheric Station between 1-21 August 2002. The temporal overlap of the two particle mass spectrometers was therefore 1-13 August 2002. In this paper we describe the full period when the 10 ATOFMS was operating, with particular emphasis on the part of the period when the two mass spectrometers were operating. A detailed overview of the AMS results can be found in Coe et al. (2005) ${ }^{1}$ whilst a detailed analysis of the ATOFMS data can be found elsewhere (Dall'Osto et al., 2004).

An isokinetic inlet system was attached to the sampling tower available at the Mace 15 Head Atmospheric Research Station, and delivered ambient air to an air-conditioned container van in which the two particle mass spectrometers were housed. The sampling height of the inlet was alternated between 7 and $22 \mathrm{~m}$ hourly by switching a valve in the pipe at $7 \mathrm{~m}$ height. The inlet system is described in detail in Coe et al. (2005) ${ }^{1}$. Data analysis showed no significant differences in the particle populations sampled at the two heights for particles in the size range $30 \mathrm{~nm}$ to $3 \mu \mathrm{m}$ diameter (Coe et al., $\left.2005^{1}\right)$.

${ }^{1}$ Coe, H., Allan, J. D., Alfarra, M. R., Bower, K. N., Flynn, M. J., McFiggans, G. B., Topping, D. O., Williams, P. I., O'Dowd, C. D., Dall'Osto, M., Beddows, D. C. S., and Harrison, R. M.: Chemical and Physical Characteristics of Aerosol Particles at a remote coastal location, Mace Head, Ireland, during NAMBLEX, Atmos. Chem. Phys. Discuss., submitted, 2005.

\section{ACPD}

5, 10799-10838, 2005

\section{Studies of aerosol using two aerosol mass spectrometers}

M. Dall'Osto et al.

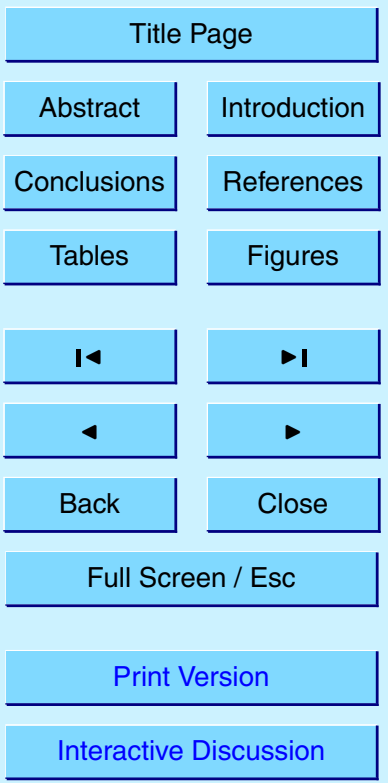

EGU 
The general techniques and history of online particle mass spectrometers were reviewed recently by Suess and Prather (1999). The basic principle of an aerosol mass spectrometer is to introduce airborne particles into the instrument, vaporise and ionise 5 the material. Once the ions are formed, they are analysed by mass spectrometry.

There are few studies in which different particle mass spectrometers have been deployed simultaneously. During August 1999 the Atlanta Supersite Project took place in Atlanta, GA and four particle mass spectrometers were operated for the first time (Middlebrook et al., 2003). During this study the ATOFMS TSI prototype (Prather et al., 1994) and an Aerodyne's AMS were compared for the first time with other single particle mass spectrometers.

In Europe, during the MINOS campaign (Crete, August 2001), an Aerodyne Aerosol Mass Spectrometer and a single particle mass spectrometer (SPLAT) were run together (Schneider et al., 2004), although the preliminary state of development of the SPLAT did not allow a full comparison.

The most widespread commercially available particle mass spectrometers are the Aerosol Mass Spectrometer (AMS-Aerodyne Research, Inc.) and Aerosol Time-ofFlight Mass Spectrometer (ATOFMS, model 3800-TSI Inc.) and a brief overview of these instruments is given in the next subparagraphs.

\subsubsection{TSI model 3800 Aerosol Time-of-Flight Mass Spectrometer (ATOFMS)}

The ATOFMS provides continuous, real-time detection and characterization of single particles from polydisperse samples, providing information on particle size and composition (Prather et al., 1994; Gard et al., 1997). Briefly, air is introduced into a vacuum system region through a converging nozzle and two skimmers create a narrow col-
5, 10799-10838, 2005

\section{Studies of aerosol using two aerosol mass spectrometers}

M. Dall'Osto et al.

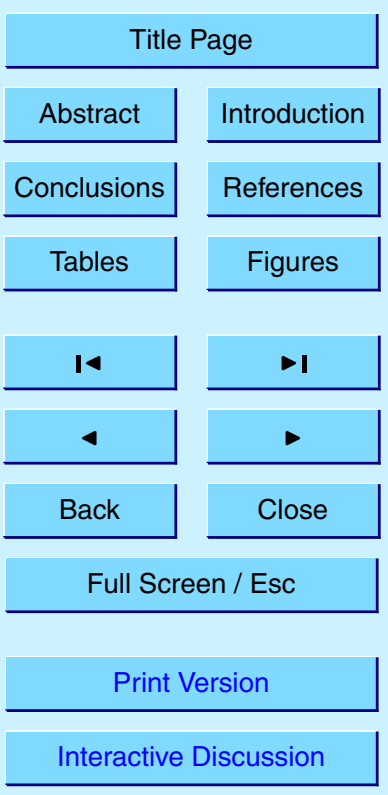

EGU 
ticles enter the mass spectrometer source region where a pulse from a Nd:YAG laser (frequency quadrupled, $\lambda=266 \mathrm{~nm}$ ) is triggered at the appropriate time - based on the transit time of the particle measured in the sizing region - to desorb and ionise material from the sized particle. The mass-to-charge ratios of both positive and negative ions 5 of single particles are then determined simultaneously in two time-of-flight reflectron mass spectrometers. The sampling efficiency of the ATOFMS is roughly proportional to the third power of the diameter (Allen et al., 2000).

During NAMBLEX, an Aerodynamic Particle Sizer (APS; Model 3320, TSI Inc. Shoreview, MN) and a Micro-Orifice Uniform Deposit Impactor (MOUDI; MSP Corporation, 10 Minneapolis, Minnesota, USA) were deployed concurrently with the ATOFMS. A comparison between ATOFMS, APS and MOUDI measurements can provide a better knowledge of the ATOFMS particle detection efficiency in a remote marine environment such as Mace Head (Dall'Osto, 2005), submitted to Environmental Science and Technology). Briefly, it was found that the response of the ATOFMS follows a power 15 law dependency in the range $0.53-1.9 \mu \mathrm{m}$, and is affected by a substantial matrix effect in the super-micron size mode depending on the chemical composition of the aerosol sampled at the time, which is reflected in variations in the hit-rate of particles with the main desorption-ionization laser as they enter the sensing zone of the instrument. It is currently a matter of debate whether this effect is due to the inherent absorptive 20 properties of the particles, or due to the hygroscopic properties and a low hit rate for solution droplets (Dall'Osto et al., 2005²; Moffet et al., 2004).

However, the laser ablation technique can provide quantitative information on an ensemble of particles of a similar matrix (Gross et al., 2000; Bhave et al., 2002). The unique feature of the ATOFMS is it can provide information on real-time changes in 25 the size-resolved mixing state (internal/external) of the single particle sampled. The instrument used in this study is able to measure the size and the chemical composition

${ }^{2}$ Dall'Osto, M., Harrison, R. M., Beddows, D. C. S., Freney, E. J., Heal, M. R., and Donovan, R. J.: Single particle detection efficiencies of aerosol time-of-flight mass spectrometry during the NAMBLEX marine boundary layer experiment, Environ. Sci. Technol., submitted, 2005.
ACPD

$5,10799-10838,2005$

\section{Studies of aerosol using two aerosol mass spectrometers}

M. Dall'Osto et al.

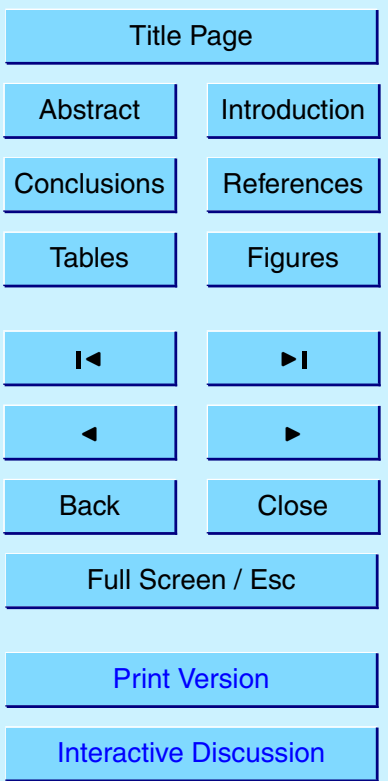

EGU 

model 3800).

\subsubsection{Aerodyne Aerosol Mass Spectrometer (AMS)}

The Aerodyne Aerosol Mass Spectrometer (AMS) (Jayne et al., 2000; Jimenez et al., 5 2003; Allan et al., 2003a) provides online, real time measurements of the mass of nonrefractory components of aerosol particles as a function of their size. Briefly, the AMS draws sample air into a high vacuum through a critical orifice and focuses particles with an aerodynamic lens. The particle diameter is measured by the same principle used in the ATOFMS which is time-of-flight. A chopper wheel delivers a slug of particles into the time of flight vacuum region, where their speed is proportional to their size. The particle beam is then delivered onto a heated surface, maintained at $500^{\circ} \mathrm{C}$, at a vacuum pressure of $10^{-8}$ torr, which is located in the centre of an electron impact ioniser. Here the particles are deposited on the hot surface and the volatile and semi-volatile components of the aerosol are vaporised. The mass collection efficiency is almost $100 \%$ for spherical particles with aerodynamic diameters between 60 and $600 \mathrm{~nm}$. The molecules are then ionised by electron impact $(70 \mathrm{eV})$ and analysed by quadrupole mass spectrometry. The AMS alternates between two data acquisition modes: the "Time-of-flight" (ToF) mode and the "Mass Spec" (MS) mode (Jimenez et al., 2003; Alfarra et al., 2004). In the ToF mode the quadrupole mass spectrometer is set to scan pre-selected fragment ions and measure their mass as a function of the particle size. In the MS mode the averaged chemical composition of the non-refractory aerosol components is determined by scanning the full mass spectrum (1-300 $\mathrm{m} / \mathrm{z}$ units) with the quadrupole mass spectrometer. In this mode the AMS measures the ambient submicron aerosol ensemble.

25 The AMS can quantify the size resolved organic carbon, sulphate, ammonium and nitrate mass loadings of aerosol in the size range between 60 and $600 \mathrm{~nm}$. However, it cannot detect refractory material such as elemental carbon, dust and sea salt particles. The standard quadrupole version of the AMS cannot resolve single particle

\section{Studies of aerosol using two aerosol mass spectrometers}

M. Dall'Osto et al.

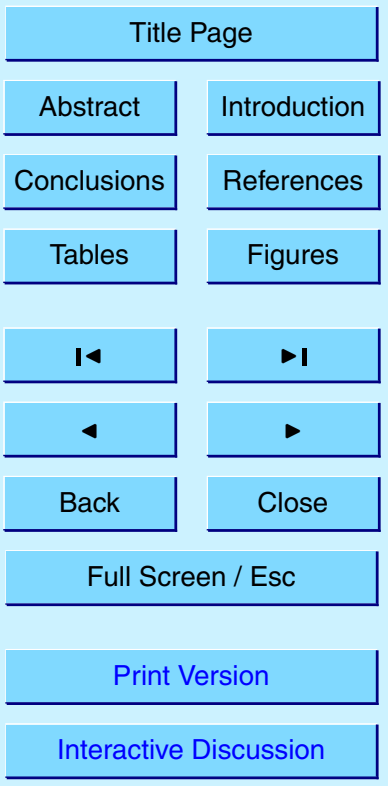

EGU 
composition, and therefore cannot explicitly determine the chemical mixing state of the particles. However, an AMS fitted with a time of flight mass spectrometer is currently being developed and will overcome this limitation.

The ATOFMS can provide mass spectral information on a single particle basis and 5 therefore information on the mixing state of single particles. Furthermore, it is sensitive to refractory material and so can probe sea salt, dust and elemental carbon, as well as more volatile components. The commercial version of the ATOFMS (without an aerodynamic lens system which is now available - TSI 3800-030) has a size dependent sampling efficiency and samples far fewer particles per unit time than the AMS.

10 The complementarity of the two particle mass spectrometers is a very powerful combination for characterising ambient particles as shown herein.

\subsection{Data collection, processing and analysis}

The ATOFMS is controlled by the TSI operational software called MS-control. It is a Windows ${ }^{\circledR}$-based, $\mathrm{C}++$ program that controls instrument operation. MS-control also 15 displays particle size, mass spectra, and time of detection for each individual particle in real time and saves all this information in raw data, which can be written in a database (Microsoft $^{\circledR}$ Access 2000 based) by another software called MS-analyse. To qualify a mass/charge $(\mathrm{m} / \mathrm{z})$ ratio as a peak, a spectrum value had to be 20 units above a user-selected baseline, contain 20 square units of area and represent at least 0.005 as fraction of the total peak area of its spectrum.

In the AMS, mass loadings are retrieved from the ion signal and mass spectral information produced based on algorithms described in Allan et al. (2003a); these will not be described in full here, but rely on ammonium nitrate calibrations to provide the main method of mass calibration. The AMS gives different information on the aerosols sampled, but a much reduced amount of data compared to the ATOFMS. The data analysis is more user-friendly and this is one of the main reasons for its more widespread use by the global scientific community. At the moment the ratio between AMS and ATOFMS

ACPD

5, 10799-10838, 2005

\section{Studies of aerosol using two aerosol mass spectrometers}

M. Dall'Osto et al.

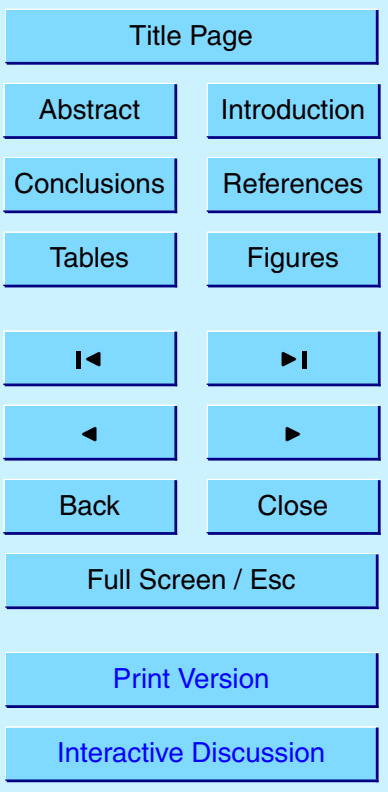

EGU 
instrument uptake by the global scientific community is roughly 3 (TSI, personal communication).

The TSI ATOFMS dataset is usually analysed by "query and search" methods, which assign each particle to groups predetermined by the user (Beddows et al., 2004; 5 Dall'Osto et al., 2004; Yadav et al., 2004). This method requires much time and is strongly affected by the marker chosen to define a specific type of single particle mass spectrum.

YAADA (Yet Another ATOFMS Data Analyzer) is a software toolkit to analyze single particle mass spectral data including data collected with Aerosol Time-of-Flight Mass

10 Spectrometer (ATOFMS) instruments. (J. O. Allen, 2001, software tool kit manual, http://www.yaada.org). The software has been widely used in the prototype version of the ATOFMS (Pastor et al., 2003; Moffet et al., 2004; Wenzel and Prather, 2004). The newest version of YAADA ( $\vee 1.30)$ is an object-oriented toolbox written in the Matlab programming (minimum Matlab version 6.5 required) and is able to import also TSI15 ATOFMS datasets. Once imported, TSI ATOFMS dataset can be analysed with the powerful ART-2a tool. ART-2a is an artificial intelligence algorithm that sorts single particle mass spectra into specific particle type or clusters (Song et al., 1999; Allen et al., 2000; Pastor et al., 2003).

The main parameters involved are the vigilance factor (VF), learning rate (LR) and 20 number of iterations though which the algorithm runs. An Art-2a cluster can be represented as an area (that varies with VF), around the weight vector that contains similar single particle mass spectra. Further details of the method can be found elsewhere (Song et al., 1999; Allen et al., 2000; Pastor et al., 2003).

\section{Results}

25 A comparison between the two real time particle mass spectrometers at Mace Head during NAMBLEX was not straightforward. The two instruments were operating at the same time only for a limited period of the campaign (1-13 August 2002). AMS

\section{ACPD}

5, 10799-10838, 2005

Studies of aerosol using two aerosol mass spectrometers

M. Dall'Osto et al.

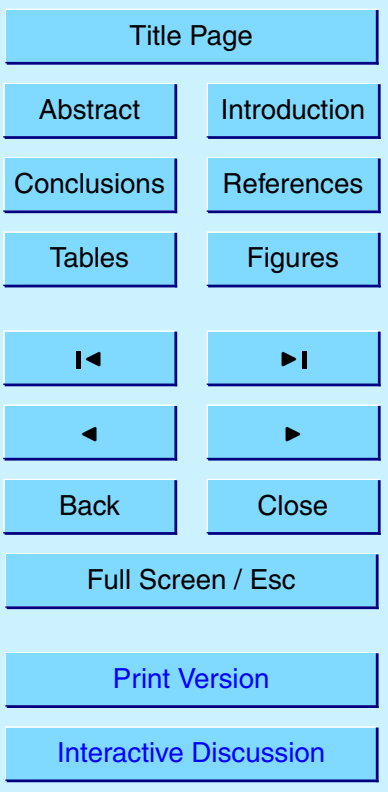

EGU 
can quantify the size resolved organic carbon, sulphate, ammonium and nitrate mass loading of aerosol in the size range between 60 and $600 \mathrm{~nm}$. However, it cannot detect refractory material such as elemental carbon, dust and sea salt particles. During the overlap period the air masses were generally clean (not influenced by anthropogenic 5 sources) and the mass loading of chemical species detected by the AMS was generally low. In contrast, the ATOFMS can detect both refractory and non-refractory material, although not in such a easily quantifiable way as the AMS.

The analysis presented here is based mainly upon ATOFMS results. AMS data are discussed when an overlap between the two instrument is helpful. For more detailed 10 information regarding the AMS dataset, the reader is referred to Coe et al. $(2005)^{1}$. The reader is invited to refer also to Dall'Osto et al. (2004), where detailed analysis of the ATOFMS data obtained by manual classification of single particle mass spectra can be found.

In Aerosol Time-of-Flight Mass Spectrometry (ATOFMS) particles for which both size 15 and mass spectra (positive and/or negative) are collected are classified as "hit". Particles which are sized but did not produce a mass spectrum are classified as "missed". In all, during NAMBLEX 1410145 particles were recorded of which 191504 were classified as hits. By running ART-2a (learning rate 0.05 , vigilant factor $0.85,20$ iterations) 244 clusters were found. $90 \%$ of the particles were classified within the top 27 clus20 ters. The top 50 clusters were able to describe $96.5 \%$ of the particles sampled at Mace Head during NAMBLEX.

The number of clusters was further reduced. Some of the top 50 clusters were very similar to each other. The main differences were due to the peak area or to the noise level. The clusters considered needed to meet the following criteria in order to and similar mass spectra in order to be merged. By merging similar clusters, the total number of clusters describing the NAMBLEX database was reduced to 17 clusters, as shown in Table 1.

Results are consistent with manual clustering of the data according to simple selec-

ACPD

5, 10799-10838, 2005

\section{Studies of aerosol using two aerosol mass spectrometers}

M. Dall'Osto et al.

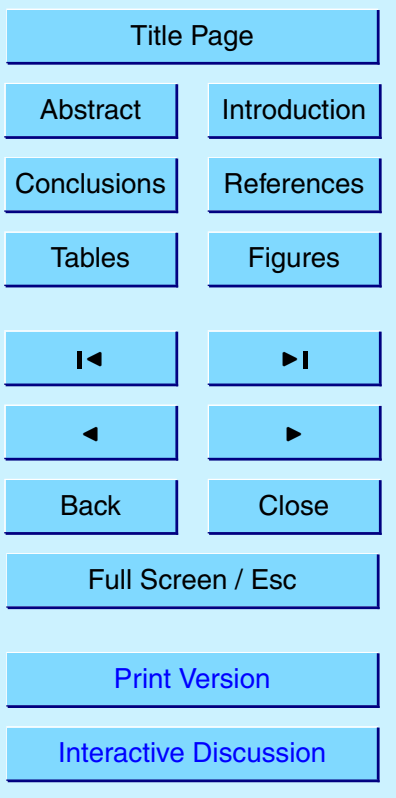

EGU 
tion rules as in Dall'Osto et al. (2004), and in Table 2 information from both classifications can be found. The rigid manual classification leaves $29 \%$ of the particles sampled unclassified, whilst the neural network algorithm ART-2a apportion the whole dataset. The two main classes Carbon-containing and Dust particles (class number 1 and 2 in 5 Table 2, respectively) are very similar in estimated percentage abundances. Class 3 (sea-salt particles) are quite different in estimated abundance and the reason will be explained in Sect. 3.1. However, the comparison between the two methods shows that ART-2a provides more detailed results (but similar to the manual classification) in a shorter amount of time.

\subsection{Inorganic classes}

As expected, sea salt was the main class, accounting for $69.2 \%$ of the particles generating mass spectra. It is important to note that the efficiency of the ATOFMS is very different for different types of particles. For example, a carbon-containing particle is more detectable (sized, desorbed and ionised by the ATOFMS) than a pure sea-salt 15 particle by at least 1 order of magnitude (Dall'Osto et al., $2005^{2}$ ). Therefore, without scaling applied, the percentages of the clusters are not representative of actual abundance and reflect the number of particles detected by the ATOFMS and not the real source apportionment of the classes present in the ambient air sampled. However, they are reported as qualitative information. The issue of quantification is addressed 20 elsewhere (Dall'Osto et al., $2005^{2}$ ).

Pure sea salt $(1 \mathrm{~A})$ represented the main sub-class, with $22.3 \%$ of the total particles sampled. A detailed description of different types of sea salt particles and several examples of single particle mass spectra are given in Dall'Osto et al. (2004). The results obtained with the ART-2a algorithm are similar to those described in Dall'Osto 25 et al. (2004), where a time consuming manual classification was required in order to classify different single particle mass spectra.

Sea-salt aerosols can react with $\mathrm{HNO}_{3}$ to form nitrate and release hydrogen chloride to the gas phase (Harrison and Pio, 1983; Harrison et al., 1994; Pakkanen, 1996; 10810
ACPD

5, 10799-10838, 2005

Studies of aerosol using two aerosol mass spectrometers

M. Dall'Osto et al.

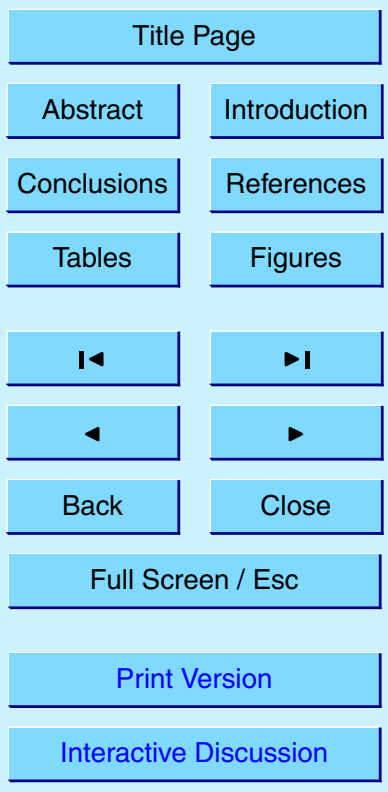

EGU 
Gard et al., 1998). Cluster $1 \mathrm{C}$ is characterised by $\mathrm{Na}_{x} \mathrm{Cl}_{y} \mathrm{NO}_{z}$ peaks whilst cluster $1 \mathrm{~F}$ shows $\mathrm{Na}_{x} \mathrm{NO}_{y}$ clusters. The temporal trends of these classes are in line with the ones presented in Dall'Osto et al. (2004), where a detailed analysis of the types of single particle mass spectra belonging to these clusters can be found.

Cluster 1D (9\%) (Fig. 1) shows a strong peak at $\mathrm{m} / \mathrm{z}-93\left(\mathrm{NaCl}_{2}^{-}\right)$together with peaks characteristic of the nitrate ion $(\mathrm{m} / \mathrm{z}=46$ and 62$)$ and correlates with polluted episodes. This class correlates with classes $1 \mathrm{C}$ and $1 \mathrm{~F}$, most likely due to pollution events. Cluster 1B (19.3\%) presents only positive ion mass spectra (very similar to the positive spectra of cluster $1 \mathrm{~A}$ ) with no information on the negative one. This could 10 be due to the negative data acquisition board overheating or another type of sea salt particle. The difference in percentage of the main sea-salt class (class number 1 in Table 2) between the two different classifications is mainly due to this cluster. Due to the lack of the negative spectra, this cluster was put into the unclassified part of the manual classification. Further studies need to be carried out in order to understand the 15 origin of this type of particle. However, it is important to note that cluster $1 \mathrm{~A}, 1 \mathrm{C}$ and $1 \mathrm{~F}$ (pure, mixed and aged sea-salt particles, respectively) presented very similar temporal trends as the same classes described in Dall'Osto et al. (2004).

Relative humidity might be expected to have some influence on the ionisation process through the hygroscopicity of the particles. Inorganic aqueous aerosols typically have higher ionisation thresholds and produce lower ion currents (Neubauer et al., 1997). Moffet et al. (2004) recently found lower ATOFMS efficiency during episodes of high $\mathrm{RH}$, causing condensation of water on particle surfaces. The relative humidity of the inlet was not controlled during our study. The $\mathrm{RH}$ of ambient air sampled during NAMBLEX was $87 \pm 16 \%$ whilst the ambient temperature was $15 \pm 4^{\circ} \mathrm{C}(95 \%$ confidence). However, part of the sampling line was inside the air conditioned container van housing the aerosol time-of-flight mass spectrometer. The container van housed several other instruments measuring different atmospheric aerosol properties which generated heat, keeping the temperature of the van always high, roughly at $30 \pm 3^{\circ} \mathrm{C}$. Air with $87 \%$ relative humidity at $15^{\circ} \mathrm{C}$ will have an $\mathrm{RH}$ of $35 \%$ at $30^{\circ} \mathrm{C}$, whilst in the

ACPD

5, 10799-10838, 2005

\section{Studies of aerosol using two aerosol mass spectrometers}

M. Dall'Osto et al.

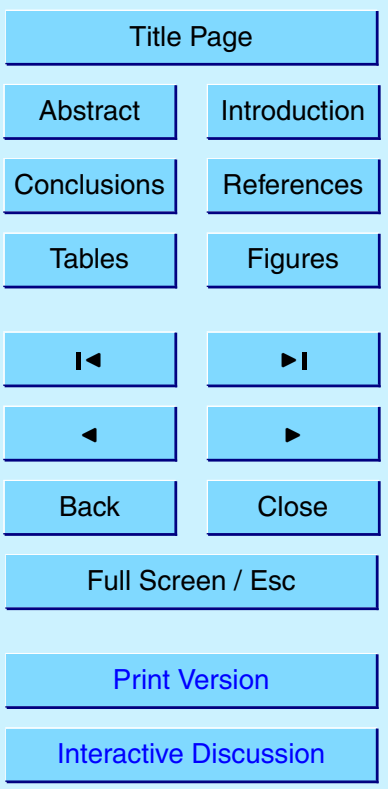

EGU 
extreme case of air saturated at $20^{\circ} \mathrm{C}$, the $\mathrm{RH}$ at $30^{\circ} \mathrm{C}$ will be only $55 \%$. We therefore consider it unlikely that particles entered the ATOFMS as solution droplets, and therefore consider that chemical matrix effects influencing absorption of the LDI laser are the most probably explanation of the lower hit rates encountered in clean air. We controversial.

Cluster 1E (Fig. 2) is characterised by strong signal at $\mathrm{m} / \mathrm{z} 24$ and its temporal trend over the entire ATOFMS operational period is shown in Fig. 3. The positive ion mass spectrum shows other peaks at $\mathrm{m} / \mathrm{z} 25$ and $\mathrm{m} / \mathrm{z} 26$, due to the isotopic distribution 10 of magnesium. The peak at $\mathrm{m} / \mathrm{z} 23$ is due to sodium, whilst the peaks at $\mathrm{m} / \mathrm{z} 39$ and $\mathrm{m} / \mathrm{z} 41$ are due to potassium. As already discussed in Dall'Osto et al. (2004), the maximum pure sea salt production occured when air was coming from the clean sector $\left(180-250^{\circ}\right)$ at high wind speed. The Mg-rich particle type was also detected only during periods of fresh sea salt particle production. The size distribution of this 15 unique type of particle is similar to the pure sea salt particles, showing a mono-modal distribution peaking at $1.6 \mu \mathrm{m}$ (as determined amongst the hit particles detected by the instrument) which remains at around $1.6 \mu \mathrm{m}$ when a sensitivity scaling factor is applied to the data over the range $0.5-2.8 \mu \mathrm{m}$ (Dall'Osto et al., $2005^{2}$ ). This class is thought to be a biogenic particle. Chlorophyll, which is an essential component of marine 20 phytoplankton is comprised of a cyclic organic structure, co-ordinated to a central atom of magnesium.

A further single particle mass spectrum belonging to this class is shown in Fig. 4.

It has a strong $[\mathrm{Mg}]^{+}$signal at $\mathrm{m} / \mathrm{z} 24$ and $\left[\mathrm{MgCl}_{3}\right]^{-}$at $\mathrm{m} / \mathrm{z}-129$ with the $\mathrm{Cl}$ isotopic distribution. There is a weak peak due to carbon at $\mathrm{m} / \mathrm{z} 12$ and $\mathrm{m} / \mathrm{z} 36$. There are indications of $\mathrm{m} / \mathrm{z} 56$, perhaps due to iron, an important ion present in biogenic particles. A weak peak at $\mathrm{m} / \mathrm{z} 77$ could be an indication of the presence of aromatic compounds $\left(\left[\mathrm{C}_{6} \mathrm{H}_{5}\right]^{+}\right)$. About $5 \%$ of particles in this class showed the enhanced spectrum exemplified by Fig. 4; the majority were more similar to Fig. 2. Due to its probable biogenic origin, this class will be further described in the next section, along with
ACPD

5, 10799-10838, 2005

\section{Studies of aerosol using two aerosol mass spectrometers}

M. Dall'Osto et al.

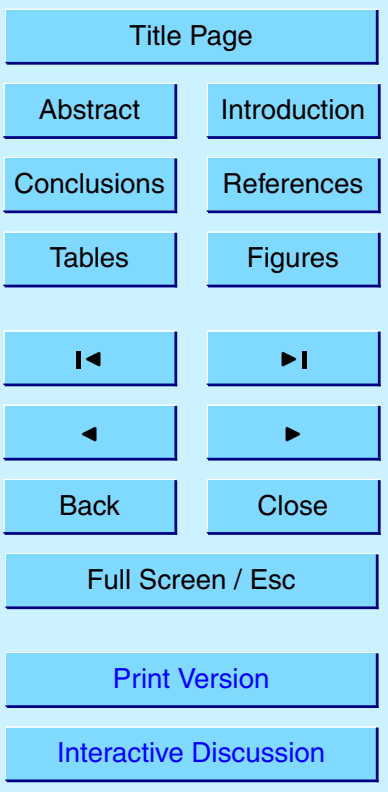

EGU 
organic-containing particle types. The AMS results will help to provide further insight into this class.

Two types of dust particles were found during the campaign (3A and 3B in Table 1), one Ca-rich due to a more local source and with little temporal variation, and the other 5 Al-Si rich due to Saharan dust particles with a strong peak on 6/12/13/14 August 2002 when back trajectories revealed transport from the Sahara. Again, further detailed information can be found in Dall'Osto et al. (2004).

\subsection{Organic classes}

\subsubsection{Local isolated episodes}

10 A local episode of carbon rich-particles was recorded on 5 August between 01:00 and $02: 00 \mathrm{~h}$ (cluster $2 \mathrm{E}$ in Table 1). A single particle mass spectrum of this specific class is shown in Fig. 5. Peaks due to $\mathrm{NaCl}(\mathrm{m} / \mathrm{z} 23, \mathrm{~m} / \mathrm{z} 81$ and $\mathrm{m} / \mathrm{z}-93), \mathrm{KCl}(\mathrm{m} / \mathrm{z} 97$ and $\mathrm{m} / \mathrm{z} 113)$ and lead ( $\mathrm{m} / \mathrm{z} 208)$ can be seen. On further analysis of these single mass spectra, an association with carbon was also found (m/z 12 and $\mathrm{m} / \mathrm{z}-24)$. These

15 particles were the only lead-containing particles detected during the campaign and they might have been generated from a combustion source near the site. Surprisingly, these particles exhibited a size distribution mode around $700 \mathrm{~nm}$, which may be the reason that the AMS did not see any difference during this period. The AMS would have seen a small mode in the organic size distribution and an aliphatic mass spectral

signature if combustion particles were present. It would not have seen supermicron particles, but a combustion source would have a significant sub-100 nm mode, unless aged highly.

The AMS nevertheless, on 10 August 2002 between 18:00 and 19:00 h detected a notable excursion of the organic mass concentration which leapt from less than $1 \mu \mathrm{g}$ 25 $\mathrm{m}^{-3}$ to around $4 \mu \mathrm{g} \mathrm{m}^{-3}$. At this time, the inlet was set to sample at $7 \mathrm{~m}$ and a casual observation was made that some motorboats were operating a short distance off the coast. The ATOFMS detected a small spike of organic-containing particles during the

\section{ACPD}

5, 10799-10838, 2005

Studies of aerosol using two aerosol mass spectrometers

M. Dall'Osto et al.

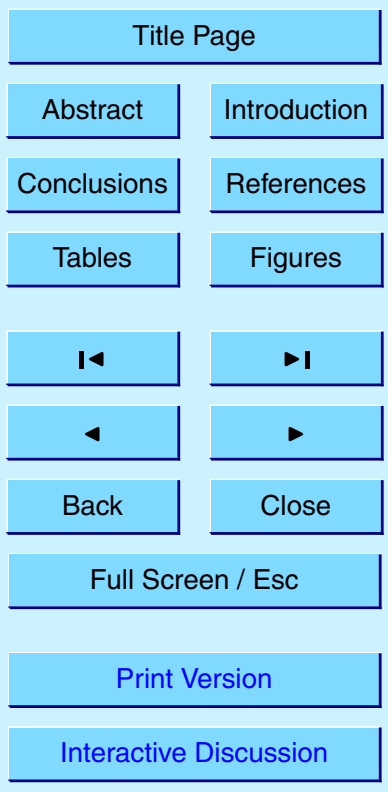

EGU 
same hour.

Three other types of carbon clusters are listed in section 2D of Table 1. They represent $\mathrm{Na}-\mathrm{EC}, \mathrm{NaCl}-\mathrm{SO}_{\mathrm{x}}$ and $\mathrm{NaCl}-\mathrm{C}$. The spectra are characterized by sodium with elemental carbon (Na-EC; main peaks $\mathrm{m} / \mathrm{z}$ 12, 23, 36 and $\mathrm{m} / \mathrm{z}-24,-36,-48$ ), sodium 5 chloride with sulphate ( $\mathrm{NaCl}-\mathrm{SO}_{x}$; main peaks $23,-35$ and -96) and sodium chloride with carbon ( $\mathrm{NaCl}-\mathrm{C}$; main peaks $\mathrm{m} / \mathrm{z} \mathrm{12,} \mathrm{23,} 36$ and -35). These three clusters did not present strong temporal trends and few particles were apportioned to them, mainly within polluted episodes as described in the next section. The average spectra, not shown, present a broad monomodal size distribution between 1.5 and $2.0 \mu \mathrm{m}$. Ox-

10 carbon (cluster $4 \mathrm{C}$ ) is another specific type of spectrum characterized by $\mathrm{m} / \mathrm{z} 27$ and $\mathrm{m} / \mathrm{z} 43$, which we attribute to $\left[\mathrm{C}_{2} \mathrm{H}_{3}^{+}\right]$and $\left[\mathrm{C}_{2} \mathrm{H}_{3} \mathrm{O}^{+}\right]$, respectively, although other interpretations are possible. This cluster did not occur very often, and only during polluted episodes.

\subsubsection{General carbon classes}

15 Three broad classes of carbon-containing particles were apportioned during NAMBLEX. Clusters $2 \mathrm{~A}, 2 \mathrm{~B}$ and $2 \mathrm{C}$ represent carbon-containing particles and carbon/sulphate-containing particles and elemental carbon (EC), respectively. The correlation between them is very good $\left(R^{2}>0.85\right)$ and their temporal trends are shown in Fig. 6. EC apportions for a much smaller fraction (1.6\%) in comparison to cluster $2 \mathrm{~A}$

20 and $2 \mathrm{~B}$, but the spikes of this type of particle were correlated with the other types of carbon-containing particles.

The broad carbon-containing particles class comprises two main clusters: carboncontaining particles and carbon/sulphate-containing particles and their spectra can be found in Figs. 7 and 8 . It is important to note that no significant signal was recorded 25 above $\mathrm{m} / \mathrm{z} 100$. The first type presents only two peaks at $\mathrm{m} / \mathrm{z} 12$ and $\mathrm{m} / \mathrm{z} 36$, whilst the second presents a more complex signature, with sulphate $(\mathrm{m} / \mathrm{z}-97)$. The peak at $\mathrm{m} / \mathrm{z}$ 39 is probably due to the organic fragment $\left(\mathrm{C}_{3} \mathrm{H}_{3}\right)^{+}$, but could be due to potassium too. Whilst the former exhibits a monomodal distribution centred at $0.6 \mu \mathrm{m}$ in the unscaled

\section{Studies of aerosol using two aerosol mass spectrometers}

M. Dall'Osto et al.

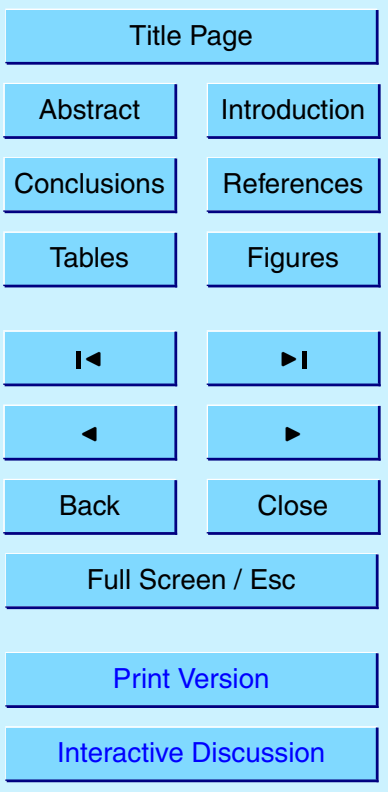

EGU 
size distribution, the latter shows a bimodal distribution peaking at 0.6 and $1.4 \mu \mathrm{m}$. The size distributions of clusters $2 \mathrm{~A}$ and $2 \mathrm{~B}$ are shown in Fig. 9.

Meteorological conditions were divided into three main distinct periods (as explained in Coe et al., 2005 ${ }^{1}$, and Norton et al., 2005). The first five days (1-5 August 2002) 5 were characterised by polluted air from Europe, with a stationary low pressure positioned over Ireland and the site experiencing NE winds, which were often light; recirculating weak fronts were present on several days. The second period (5-12 August 2002) was characterised by the Azores high extended further towards Ireland and the winds became westerly to north westerly, The third ATOFMS period (12-21 August 10 2002) was mainly characterised by air coming from the clean sector (not influenced by anthropogenic activity).

The ATOFMS observations are supported by the AMS results, as shown in Fig. 10. The overall behavior of the particles was largely very similar to the other MBL experiments conducted with the AMS (Allan et al., 2004; Topping et al., 2004), in that sulphate and organics dominated the loadings roughly equally overall with mean concentrations of 0.56 and $0.65 \mu \mathrm{g} \mathrm{m}^{-3}$, respectively, and there was only a very small contribution from nitrate, at an average of $0.05 \mu \mathrm{g} \mathrm{m}^{-3}$. Ammonium is present at an average of $0.18 \mu \mathrm{g} \mathrm{m}^{-3}$, but does not always completely neutralise the sulphate. However, the overall loadings were smaller compared to the other studies. The highest concentrations occurred around 1-5 August, when the calculated back trajectory arrived from the east, across Ireland, England and mainland Europe. In the first period (1-5 August 2002) there is more organic carbon than sulphate. In the second period (5-12 August 2002) the situation is reversed, with the sulphate load higher than carbonaceous material. It is important to remember that during the first period also the ATOFMS detected the highest number of carbon containing particles (cluster $2 \mathrm{~A}$ ), as already described above.

ACPD

5, 10799-10838, 2005

\section{Studies of aerosol using two aerosol mass spectrometers}

M. Dall'Osto et al.

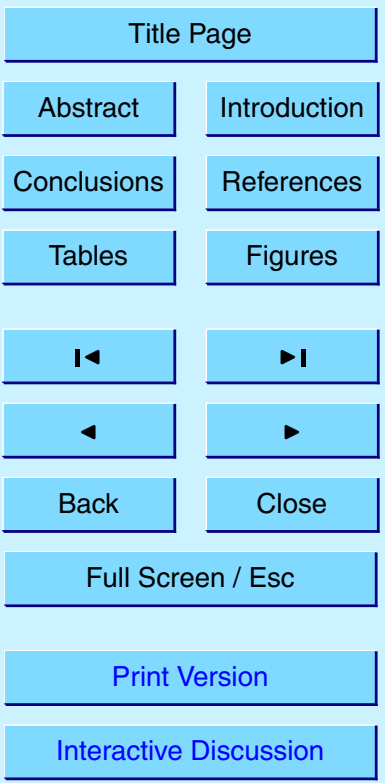

EGU 


\subsubsection{Biogenic particles}

As introduced in Sect. 3.1, cluster 1E (Fig. 2) is characterised by strong signal at $\mathrm{m} / \mathrm{z}$ 24 which is due to magnesium. This particle type was detected only during periods of fresh sea salt particle production. Recent studies conducted at University of Califor5 nia (San Diego) have reported a unique type of magnesium-rich particle found only in biologically productive environments based on simultaneous DMS and seawater chlorophyll measurements (Prather, $2005^{3}$ ). However, Prather $(2005)^{3}$ reports a detection efficiency-corrected mode in the size distribution of $<1 \mu \mathrm{m}$, whilst in our data the diameter mode is at around $1.6 \mu \mathrm{m}$, and only $2 \%$ of the unscaled particles are submicrometer. When the ATOFMS counts are scaled (Allen et al., 2000; Wenzel, 2003; Dall'Osto, 2005), the size distribution of this unique type of Mg-rich particle still peaks at around $1.6 \mu \mathrm{m}$, but the contribution to the sub-micrometer fraction increases. This cluster (1E) of Mg-rich particles represents a significant fraction of the sub-micron mode $(60 \%)$ detected with the ATOFMS during the clean periods and thus could be makal. (2004). However, there are uncertainties attached to the size distribution inferred in our study which result from the extreme inefficiency of the ATOFMS standard inlet at very small particle size (which makes the scaling factor uncertain) and which would be resolved by the use of an aerodynamic lens inlet (Su et al., 2004).

AMS results were compared in order to better understand this unique type of particle detected a Mace Head during NAMBLEX. This is taken from three periods when both instruments were operating. As seen in Fig. 11, around $1000 \mathrm{~nm}$ diameter, there is an enhancement of the organic content compared to the sulphate in the two clean cases, which would be consistent with the hypothesis that $\mathrm{Mg}$ is an indicator of the presence of organic species in the sea salt particles.

The contrast is that both in clean marine periods where Mg was not observed by

\footnotetext{
${ }^{3}$ Prather, K. A.: Atmospheric enrichment of ocean-derived biogenic particles: Single particle composition correlations with traditional indicators of biogenic activity, in preparation, 2005.
}

ACPD

5, 10799-10838, 2005

\section{Studies of aerosol using two aerosol mass spectrometers}

M. Dall'Osto et al.

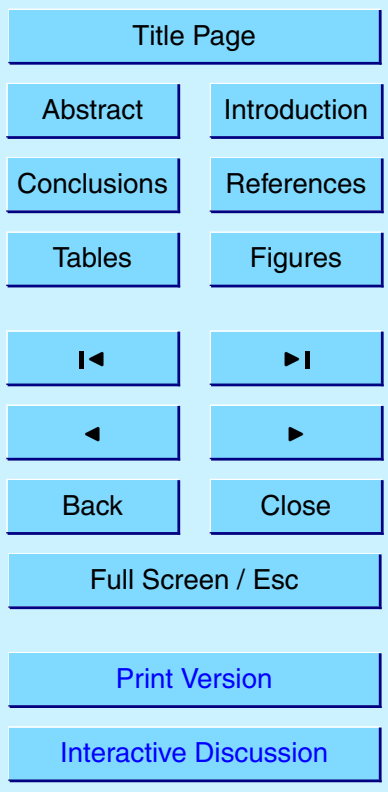

EGU 
the ATOFMS, and polluted periods, the organic and sulphate mass size distributions as measured by the AMS are very similar above $200 \mathrm{~nm}$, displaying a single broad accumulation mode centred at $350 \mathrm{~nm}$ and showing little signal above $600 \mathrm{~nm}$. In the polluted case, a large organic mode below $200 \mathrm{~nm}$ is evident, characteristic of recently 5 emitted pollution aerosol as has been seen in many urban locations previously (Allan et al., 2003b; Alfarra et al., 2004). However, when Mg-rich particles are observed by the ATOFMS, the organic mass distributions measured by the AMS show enhanced loading in the $600 \mathrm{~nm}$ to $1000 \mathrm{~nm}$ size range. As the transmission efficiency of the lens used in the AMS falls away above $600 \mathrm{~nm}$ and is close to zero at $2 \mu \mathrm{m}$ (Jayne et al., 10 2000), it is likely that a significant fraction of the organic loading in this mode is in the coarse mode above $1 \mu \mathrm{m}$.

This can also be seen in Fig. 12. The top chart shows the AMS coarse $(600-1000 \mathrm{~nm}$ aerodynamic diameter) to fine (less than $600 \mathrm{~nm}$ ) mass ratio for organics and sulphate. It should be noted that this ratio is not an absolute measure because the transmission 15 of coarse particles though the aerodynamic lens is poor. However, this chart can provide useful qualitative information. At most times the organic fraction is similar to the sulphate fraction. However, when the ATOFMS detects Mg-rich particles, the organic coarse fraction increases whereas the sulphate coarse fraction does not. This result supports the idea that Mg-rich particles detected with the ATOFMS contain organic 20 matter.

Apparent differences between our observations and those of O'Dowd et al. (2004) may have a number of explanations. Firstly, the NAMBLEX campaign was not characterised by a high level of marine biogenic activity (C. D. O'Dowd, personal communication) and also did not experience a high frequency of wind directions in the clean 25 maritime sector.

Moreover, two main instrumental issues need to be kept in mind:

1. ATOFMS efficiency for the finest size fractions $(0.06-0.25 \mu \mathrm{m})$ reported by O'Dowd et al. (2004) is very low, meaning that most of the particles in this size range are missed. The deployment of an ATOFMS with an aerodynamic lens
ACPD

5, 10799-10838, 2005

Studies of aerosol using two aerosol mass spectrometers

M. Dall'Osto et al.

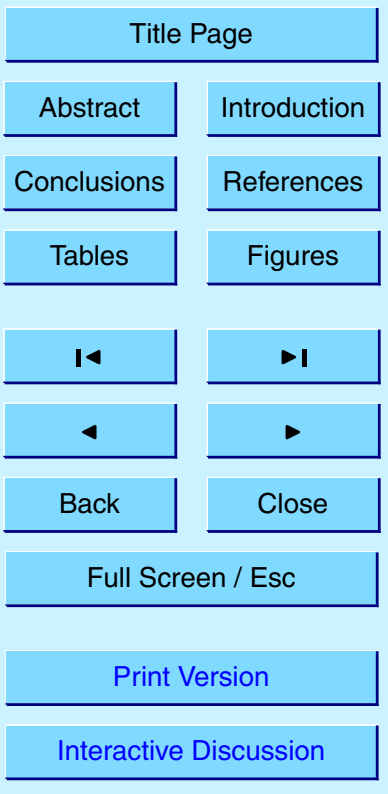

EGU 
would solve this limitation, because the efficiency in the sub-micron mode would be substantially increased (Su et al., 2004).

2. The mass loading of this biogenic particle type is not high enough to be discriminated above the background level of organic aerosols detected by the AMS during NAMBLEX having the same accumulation mode size distributions as sulphate, likely to be due to long range transport of air pollutants.

These particles may contribute significantly to the total number of particles in the submicron mode, but they were missed by the ATOFMS (due its poor efficiency in low particle size ranges). The solid line on Fig. 11 shows the mass loading of carbon 10 for the clean period with the presence of Mg-rich particles. The mass loading in the $200-400 \mu \mathrm{m}$ range is roughly double that of the sulphate. It could be that this carbon contribution is due to the biogenic particles, but because of the limitation of the ATOFMS efficiency and the absence of single particle information from the AMS, it is not possible to draw conclusions on this. Further studies need to be carried out in the same location during periods of high biogenic activity.

This Mg-particle type was found to be more abundant during episodes of heavy rain, suggesting the bubble-bursting processes could perhaps be enriched by rain droplets falling on the ocean surface as shown in Fig. 13. The highest concentrations of Mg-rich particles (relative to the total number of fresh sea salt particles) were recorded during period of intense rain, regardless of the wind speed.

In order to better understand the importance of the Mg-rich particles, ART 2a was run only on particles with $\mathrm{m} / \mathrm{z} 24.89902$ particles presented a peak at $\mathrm{m} / \mathrm{z} 24$, representing $47 \%$ of the particles detected. The peak at $\mathrm{m} / \mathrm{z} 24$ can be due either to $\mathrm{Mg}^{+}$and/or $\left[\mathrm{C}_{2}\right]^{+} .90 \%$ of the particles were classified within the top 15 clusters. Because of the frequent occurrence of the peak at $\mathrm{m} / \mathrm{z} 24$, most of the classes are similar to the ones obtained by considering all the peaks. Three clusters presented a strong $\mathrm{Mg}$ signal and the $\mathrm{Mg}$ rich type particles again correlate very well with the pure $\mathrm{NaCl}$ particles. Two of the clusters were essentially the same, with only a small difference in the intensity
ACPD

5, 10799-10838, 2005

\section{Studies of aerosol using two aerosol mass spectrometers}

M. Dall'Osto et al.

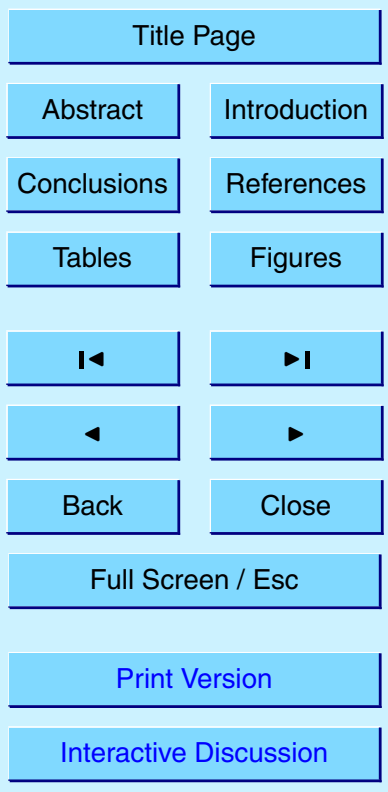

EGU 
of the potassium signal. Class 10 presents a strong signal due to $\mathrm{Mg}$, associated with a strong $\mathrm{Na}$ signal. This class did not correlate with pure sea salt. Instead, it seems to correlate with the total number of particles detected, most of which was apportioned to the main sea-salt class. Only the Mg-rich particles with a weak signal 5 due to sodium correlated with fresh sea salt particles. The available evidence suggests that these particles derive from photosynthetic organisms, presumably arising from the sea surface

\subsection{Minor classes}

The minor classes show very little temporal trends, mostly correlated with periods of 10 anthropogenic episodes. Vanadium correlates with polluted episodes. This is very a specific cluster due the high ATOFMS response to vanadium (m/z 51 and $\mathrm{m} / \mathrm{z} 67$ ) (Song et al., 1999; Allen et al., 2000; Pastor et al., 2003; Dall'Osto et al., 2004).

Amines are another type of cluster that present characteristic peaks, such as $\mathrm{m} / \mathrm{z}$ 58 and $\mathrm{m} / \mathrm{z} 86$ (Angelino et al., 2001). This type of particle was detected only when Saharan dust particles were also detected. This correlation is unexplained.

The majority of the unclassified particles (cluster 4D) presented only one or two distinguishable $\mathrm{m} / \mathrm{z}$ signals $\left(\mathrm{m} / \mathrm{z} 23[\mathrm{Na}]^{+}\right.$and/or $\left.\mathrm{m} / \mathrm{z} 39[\mathrm{~K}]^{+}\right)$in the positive spectrum and none in the negative. These particles correlated with the total number of particles detected during NAMBLEX. The ATOFMS is very sensitive to alkali metal cations 20 (Gross et al., 2000), and since sodium and potassium are present in large abundance in sea-salt particles, it is not surprising that these are the only peaks visible in some spectra.

\section{Conclusion}

The ATOFMS data analysis in this project has tested the abilities of the ART-2a algorithm versus the very laborious use of selection rules which we applied in our earlier

ACPD

5, 10799-10838, 2005

Studies of aerosol using two aerosol mass spectrometers

M. Dall'Osto et al.

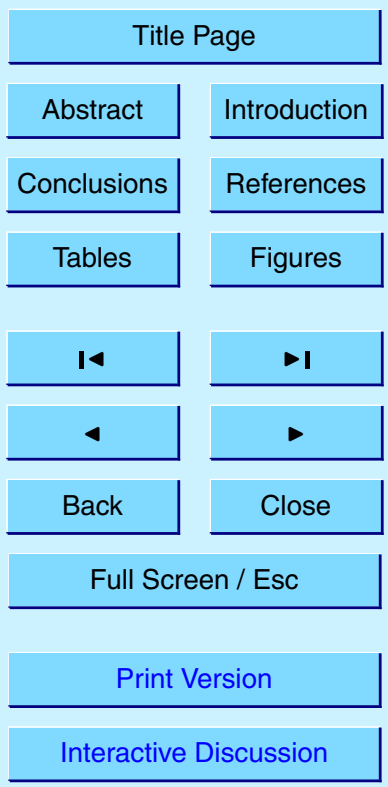

EGU 
paper (Dall'Osto et al., 2004). Reassuringly, the two very different techniques provide a very similar set of particle categories based on the three major groups of sea salt derived, carbon-based and dust particles. With these main categories a number of distinct minor categories are identifiable. The ATOFMS is a powerful instrument for 5 determining the extent of chemical processing of marine aerosol particles as well as identifying carbonaceous and dust particles from distinct source categories.

In this paper we report a type of particle not identified in our earlier data analysis. Following pioneering work by Prather et al. (2005) ${ }^{3}$ we identify a magnesium-rich particle type which appears to derive from photosynthetic plankton suspended from the

10 sea surface. Valuable complementary data supporting the ocean as a source of this particle type derives from the AMS instrument. Together, these provide a very powerful combination for characterising airborne particulate matter.

Further studies need to be carried out at the same location during period of high biological activity in order to better understand the properties of these particles.

15 Acknowledgements. The authors are grateful to the Natural Environment Research Council for funding this work as part of the NAMBLEX Consortium project coordinated by D. Heard (University of Leeds). They also thank D. C. S. Beddows (University of Wales, UK), R. P. Kinnersley (Environment Agency, UK) and M. Flynn (University of Manchester, UK) for sampling at Mace Head during NAMBLEX. Last, but not least, S. Toner (USCD) and J. O. Allan (Arizona State 20 University) for helping in importing and analyzing TSI ATOFMS data.

\section{References}

Alfarra, M. R., Coe, H., Allan, J. D., et al.: Characterization of urban and rural organic particulate in the lower Fraser valley using two aerodyne aerosol mass spectrometers, Atmos. Environ., 38(34), 5745-5758, 2004.

25 Allan, J. D., Alfarra, M. R., Bower, K. N., et al.: Quantitative sampling using an Aerodyne aerosol mass spectrometer: 2. Measurements of fine particulate chemical composition in two UK cities, J. Geophys. Res., 108(D9), art. no. 4284, 2003a.

ACPD

5, 10799-10838, 2005

Studies of aerosol using two aerosol mass spectrometers

M. Dall'Osto et al.

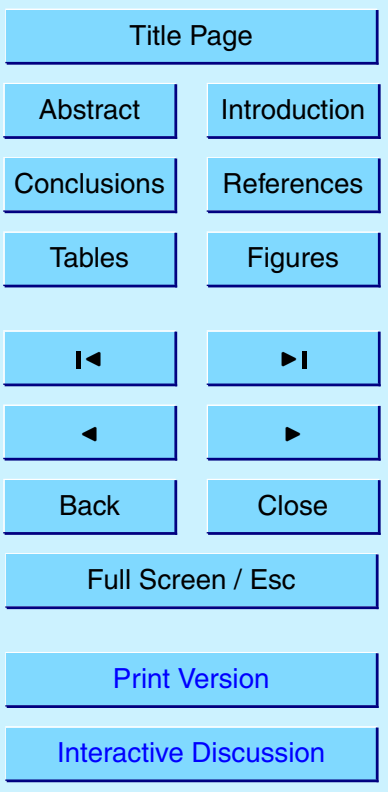

EGU 
Allan, J. D., Jimenez, J. L., Williams, P. I., et al.: Quantitative sampling using an Aerodyne aerosol mass spectrometer: 1. Techniques of data interpretation and error analysis, J. Geophys. Res., 108(D9), art. no. 4283, 2003b.

Allen, J. O., Fergenson, D. P., Gard, E. E., et al.: Particle detection efficiencies of aerosol time of 5 flight mass spectrometers under ambient sampling conditions, Environ. Sci. Technol., 34(1), 211-217, 2000.

Angelino, S., Suess, D. T., and Prather, K. A.: Formation of aerosol particles from reactions of secondary and tertiary alkylamines: Characterization by aerosol time-of- flight mass spectrometry, Environ. Sci. Technol., 35(15), 3130-3138, 2001.

10 Beddows, D. C. S., Donovan, R. J., Harrison, R. M., et al.: Correlations in the chemical composition of rural background atmospheric aerosol in the UK determined in real time using time-of-flight mass spectrometry, J. Environ. Monit., 6(2), 124-133, 2004.

Bhave, P. V., Allen, J. O., Morrical, B. D., et al.: A field-based approach for determining ATOFMS instrument sensitivities to ammonium and nitrate, Environ. Sci. Technol., 36(22), 4868-4879, 2002.

Dall'Osto, M., Beddows, D. C. S., Kinnersley, R. P., et al.: Characterization of individual airborne particles by using aerosol time-of-flight mass spectrometry at Mace Head, Ireland, J. Geophys. Res., 109(D21), art. no. D21302, 2004.

Gard, E., Mayer, J. E., Morrical, B. D., et al.: Real-time analysis of individual atmospheric aerosol particles: Design and performance of a portable ATOFMS, Anal. Chem., 69(20), 4083-4091, 1997.

Gard, E. E., Kleeman, M. J., Gross, D. S., et al.: Direct observation of heterogeneous chemistry in the atmosphere, Science, 279(5354), 1184-1187, 1998.

Gross, D. S., Galli, M. E., Silva, P. J., and Prather, K. A.: Relative sensitivity factors for alkali metal and ammonium cations in single particle aerosol time-of-flight mass spectra, Anal. Chem., 72(2), 416-422, 2000.

Harrison, R. M., Msibi, M. I., Kitto, A. M. N., and Yamulki, S.: Atmospheric ChemicalTransformations of Nitrogen-Compounds Measured in the North-Sea Experiment, September 1991, Atmos. Environ., 28(9), 1593-1599, 1994.

30 Harrison, R. M. and Pio, C. A.: Size-Differentiated Composition of Inorganic Atmospheric Aerosols of Both Marine and Polluted Continental Origin, Atmos. Environ., 17(9), 1733$1738,1983$.

Jayne, J. T., Leard, D. C., Zhang, X. F., et al.: Development of an aerosol mass spectrometer for

ACPD

5, 10799-10838, 2005

\section{Studies of aerosol using two aerosol mass spectrometers}

M. Dall'Osto et al.

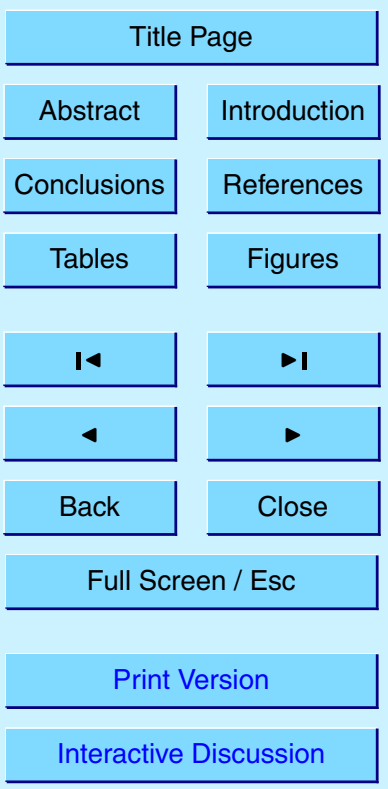

EGU 
size and composition analysis of submicron particles, Aerosol Sci. Technol., 33(1-2), 49-70, 2000.

Jennings, S. G., Geever, M., McGovern, F. M., et al.: Microphysical and physico-chemical characterization of atmospheric marine and continental aerosol at Mace Head, Atmos. Environ., $5 \quad 31(17), 2795-2808,1997$.

Jimenez, J. L., Jayne, J. T., Shi, Q., et al.: Ambient aerosol sampling using the Aerodyne Aerosol Mass Spectrometer, J. Geophys. Res., 108(D7), art. no. 8425, 2003.

Johnston, M. V. and Wexler, A. S.: On the Cover - Ms of Individual Aerosol-Particles, Anal. Chem., 67(23), A721-A726, 1995.

10 Kleefeld, S., Hoffer, A., Krivacsy, Z., and Jennings, S. G.: Importance of organic and black carbon in atmospheric aerosols at Mace Head, on the West Coast of Ireland (53 degrees 19' N, 9 degrees 54' W), Atmos. Environ., 36(28), 4479-4490, 2002.

McMurry, P. H.: A review of atmospheric aerosol measurements, Atmos. Environ., 34(12-14), 1959-1999, 2000.

15 Middlebrook, A. M., Murphy, S. M., Lee, S. H., et al.: A comparison of particle mass spectrometers during the 1999 Atlanta Supersite Project, J. Geophys. Res., 108(D7), art. no. 8424, 2003.

Moffet, R., Shields, L., Berntsen, J., et al.: Characterization of an Ambient Coarse Particle Concentrator Used for Human Exposure Studies: Aerosol Size Distributions, Chemical Composition, and Concentration Enrichment, Aerosol Sci. Technol., 38(11), 1123-1137, 2004.

Neubauer, K. R., Johnston, M. V., and Wexler, A. S.: On-line analysis of aqueous aerosols by laser desorption ionization, Int. J. Mass Spectrom., 163(1-2), 29-37, 1997.

Norton, E. G., Vaughan, G., Methven, J., et al.: Boundary layer structure and decoupling from synoptic scale flow during NAMBLEX, Atmos. Chem. Phys. Discuss., 5, 3191-3223, 2005,

25 SRef-ID: 1680-7375/acpd/2005-5-3191.

Novakov, T. and Penner, J. E.: Large Contribution of Organic Aerosols to Cloud-CondensationNuclei Concentrations, Nature, 365(6449), 823-826, 1993.

O'Dowd, C. D., Facchini, M. C., Cavalli, F., et al.: Biogenically driven organic contribution to marine aerosol, Nature, 431(7009), 676-680, 2004.

30 Pakkanen, T. A.: Study of formation of coarse particle nitrate aerosol, Atmos. Environ., 30(14), 2475-2482, 1996.

Pastor, S. H., Allen, J. O., Hughes, L. S., et al.: Ambient single particle analysis in Riverside, California by aerosol time-of-flight mass spectrometry during the SCOS97-NARSTO,

ACPD

$5,10799-10838,2005$

\section{Studies of aerosol using two aerosol mass spectrometers}

M. Dall'Osto et al.

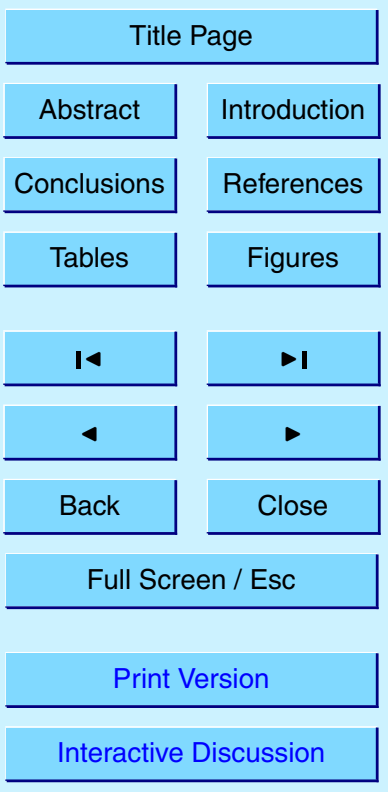

EGU 
Atmosp. Environ., 37(2), 239-258, 2003.

Prather, K. A., Nordmeyer, T., and Salt, K.: Real-Time Characterization of Individual AerosolParticles Using Time-of-Flight Mass-Spectrometry, Anal. Chem., 66(9), 1403-1407, 1994.

Raes, F., Van Dingenen, R., Vignati, E., et al.: Formation and cycling of aerosols in the global troposphere, Atmos. Environ., 34(25), 4215-4240, 2000.

Schneider, J., Borrmann, S., Wollny, A. G., et al.: Online mass spectrometric aerosol measurements during the MINOS campaign (Crete, August 2001), Atmos. Chem. Phys., 4, 65-80, 2004

SRef-ID: 1680-7324/acp/2004-4-65.

10 Song, X. H., Hopke, P. K., Fergenson, D. P., and Prather, K. A.: Classification of single particles analyzed by ATOFMS using an artificial neural network, ART-2A, Anal. Chem., 71(4), 860865, 1999.

Su, Y. X., Sipin, M. F., Furutani, H., and Prather, K. A.: Development and characterization of an aerosol time-of-flight mass spectrometer with increased detection efficiency, Anal. Chem., 76(3), 712-719, 2004.

Suess, D. T. and Prather, K. A.: Mass spectrometry of aerosols, Chem. Rev., 99(10), 30073035, 1999.

Topping, D., Coe, H. McFiggans, G., et al.: Aerosol chemical characteristics from sampling conducted on the Island of Jeju, Korea during ACE Asia, Atmos. Environ., 38(14), 21112123, 2004.

Wenzel, R. J., Liu, D.-Y., Edgerton, E. S., and Prather, K. A.: Aerosol time-of-flight mass spectrometry during the Atlanta Supersite Experiment: 2. Scaling procedures, J. Geophys. Res., 108(D7), art. no. 8427, 2003.

Wenzel, R. J. and Prather, K. A.: Improvements in ion signal reproducibility obtained using a homogeneous laser beam for on-line laser desorption/ionization of single particles, Rapid Commun. Mass Spectrom., 18(13), 1525-1533, 2004.

Yadav, R., Saoud, K., Rasouli, F., et al.: Study of cigarette smoke aerosol using time of flight mass spectrometry, J. Anal. Appl. Pyrolysis, 72(1), 17-25, 2004.

\section{ACPD}

5, 10799-10838, 2005

\section{Studies of aerosol \\ using two aerosol \\ mass spectrometers}

M. Dall'Osto et al.

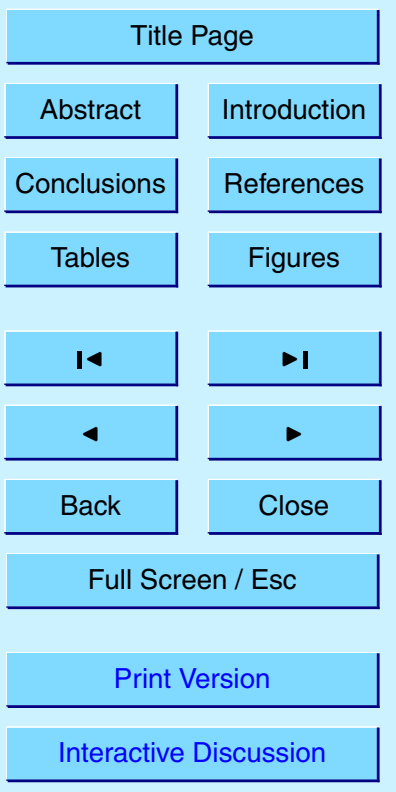

EGU 


\section{ACPD}

Table 1. Main ATOFMS clusters obtained using ART-2a.

\begin{tabular}{|c|c|c|}
\hline Cluster number & cluster type & $\%$ \\
\hline 1 & SEA SALT & 69.2 \\
\hline $1 \mathrm{~A}$ & pure $\mathrm{NaCl}$ & 22.3 \\
\hline 1B & $\mathrm{NaCl}$ only positive & 19.3 \\
\hline $1 \mathrm{C}$ & mixed $\mathrm{NaCl}_{x} \mathrm{NO}_{y}$ & 14.5 \\
\hline 1D & $\mathrm{NaCl}$ strong -93 & 9 \\
\hline $1 \mathrm{E}$ & Mg-rich & 2.6 \\
\hline $1 \mathrm{~F}$ & Aged $\left(\mathrm{NaNO}_{3}\right)$ & 2.5 \\
\hline 2 & CARBON & 20.6 \\
\hline $2 \mathrm{~A}$ & Carbon $(\mathrm{m} / \mathrm{z} 12,36)$ & 7.8 \\
\hline 2B & Carbon (m/z 12, 36 and -97) & 8 \\
\hline $2 \mathrm{C}$ & EC & 1.6 \\
\hline $2 \mathrm{D}$ & $\mathrm{Na}-\mathrm{EC}, \mathrm{NaClSO}_{x}, \mathrm{NaCl}-\mathrm{C}$ & 3.0 \\
\hline $2 \mathrm{E}$ & Combustion & 0.2 \\
\hline 3 & DUST & 4.8 \\
\hline $3 A$ & $\mathrm{AlSiO}_{\mathrm{x}}$ & 4.5 \\
\hline 3B & Ca-rich & 0.3 \\
\hline 4 & OTHER & 5.4 \\
\hline $4 \mathrm{~A}$ & Amines & 0.2 \\
\hline 4B & vanadium & 0.2 \\
\hline $4 \mathrm{C}$ & $\mathrm{O}_{\mathrm{x}}$-carbon & 0.3 \\
\hline 4D & unclassified & 4.7 \\
\hline
\end{tabular}

5, 10799-10838, 2005

Studies of aerosol using two aerosol mass spectrometers

M. Dall'Osto et al.
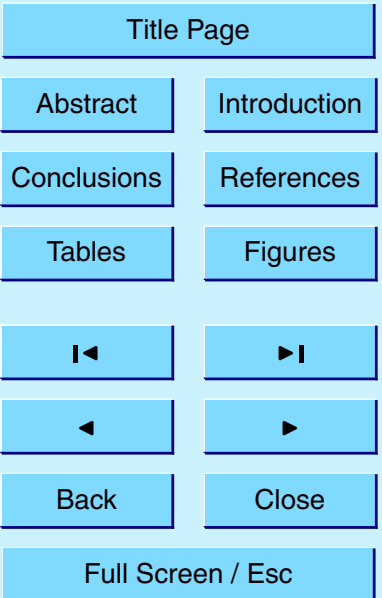

Print Version

Interactive Discussion

EGU 


\section{ACPD}

5, 10799-10838, 2005

\section{Studies of aerosol using two aerosol mass spectrometers}

M. Dall'Osto et al.

Table 2. Comparison of ART-2a analysis with previous manual analysis of the ATOFMS dataset obtained during NAMBLEX.

\begin{tabular}{cccc}
\hline $\begin{array}{c}\text { Class } \\
\text { Number }\end{array}$ & Class of particles & $\begin{array}{c}\text { Dall'Osto et al. (2004) } \\
\text { (manual classification, \%) }\end{array}$ & $\begin{array}{c}\text { This study } \\
\text { (ART-2a classification, \%) }\end{array}$ \\
\hline 1 & Carbon & 18 & 20.6 \\
2 & Dust & 5.5 & 4.8 \\
3 & Sea-salt & 47.5 & 69.2 \\
4 & Others & 0 & 5.4 \\
5 & Unclassified & 29 & 4.7 \\
\hline
\end{tabular}

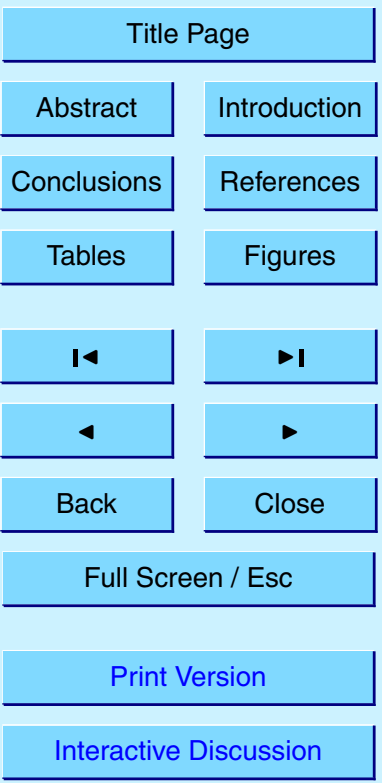

EGU 


\section{ACPD}

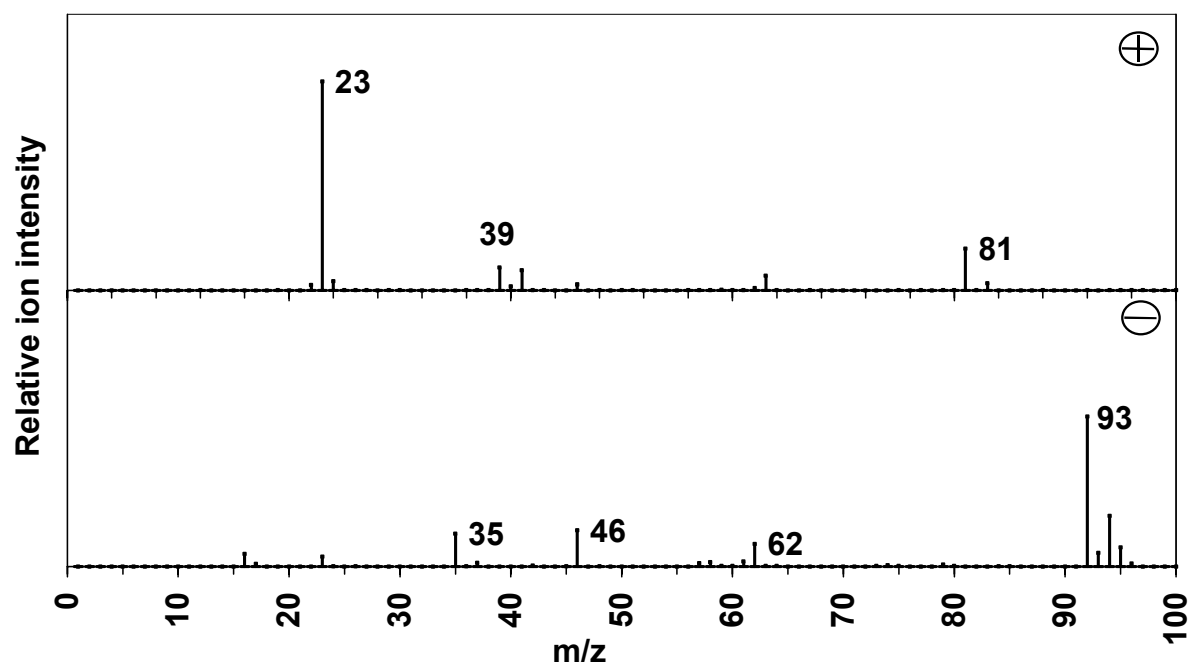

Fig. 1. ART-2a cluster (1D) positive (plus) and negative (minus) ion mass spectra of particles attributed to sodium chloride-rich with strong peak at $\mathrm{m} / \mathrm{z}-93$, likely to be sea salt particles reacted with nitric acid. Note ART-2a spectra omit minor peaks which are presented in full spectra in Dall'Osto et al. (2004).
5, 10799-10838, 2005

\section{Studies of aerosol \\ using two aerosol mass spectrometers}

M. Dall'Osto et al.

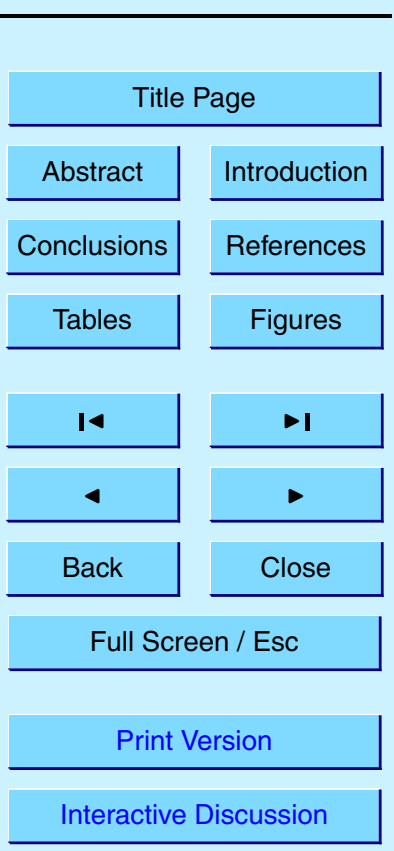

EGU 


\section{ACPD}

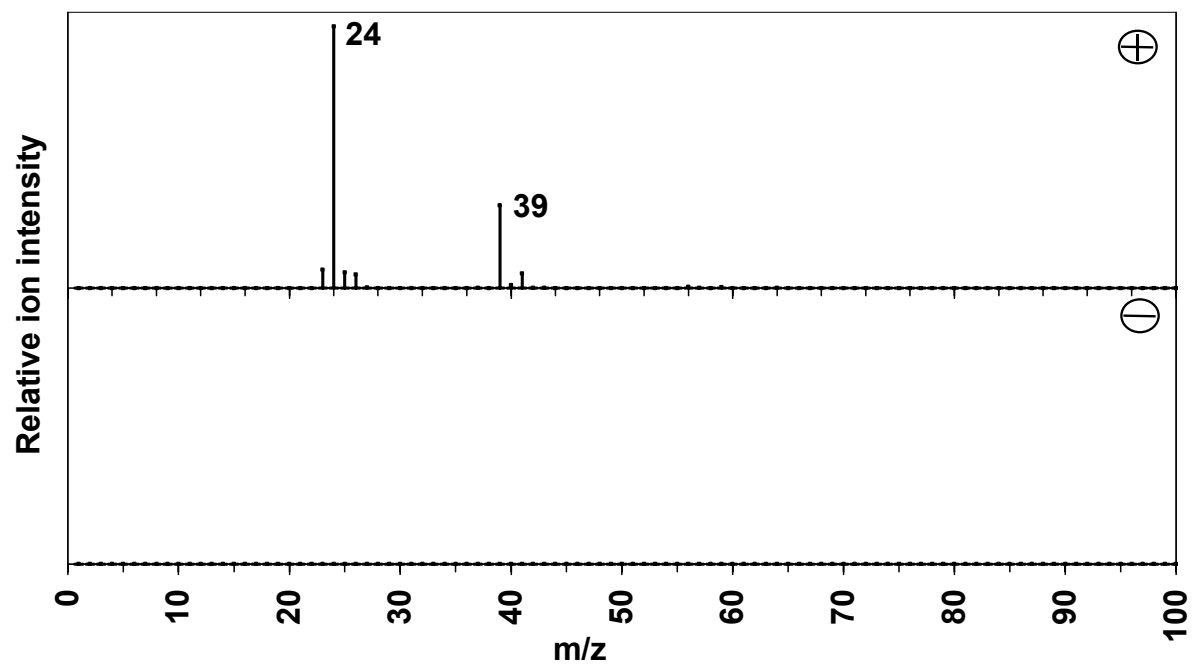

Fig. 2. ART-2a cluster (1E) positive (plus) and negative (minus) mass spectra of particles attributed to Mg-rich particles.
5, 10799-10838, 2005

Studies of aerosol using two aerosol mass spectrometers

M. Dall'Osto et al.

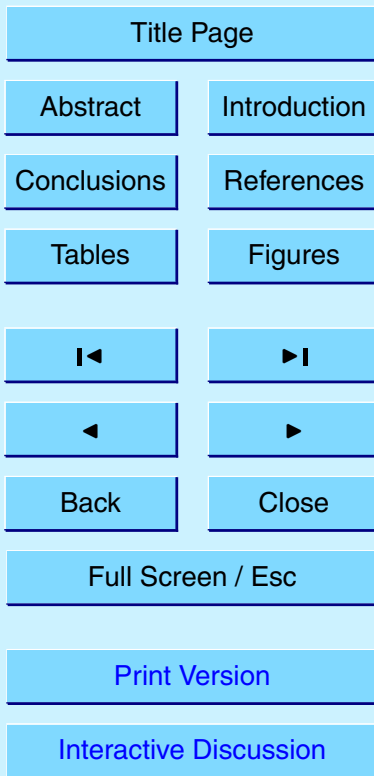

EGU 


\section{ACPD}

5, 10799-10838, 2005

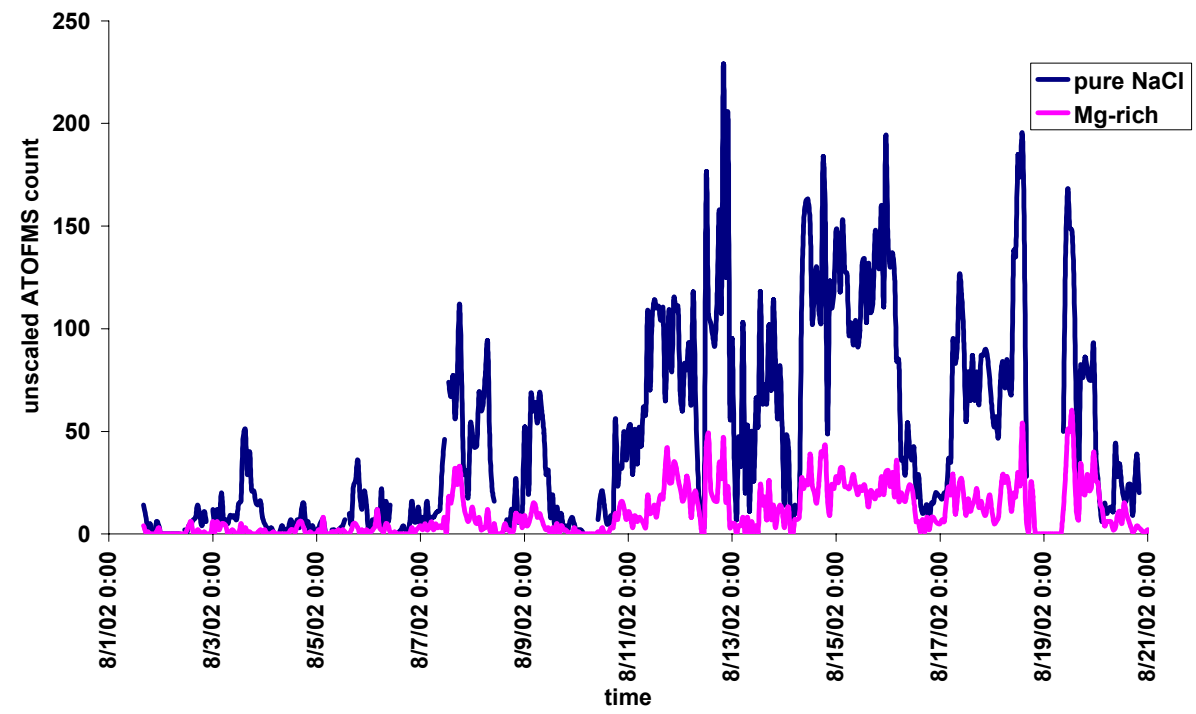

Studies of aerosol using two aerosol mass spectrometers

M. Dall'Osto et al.

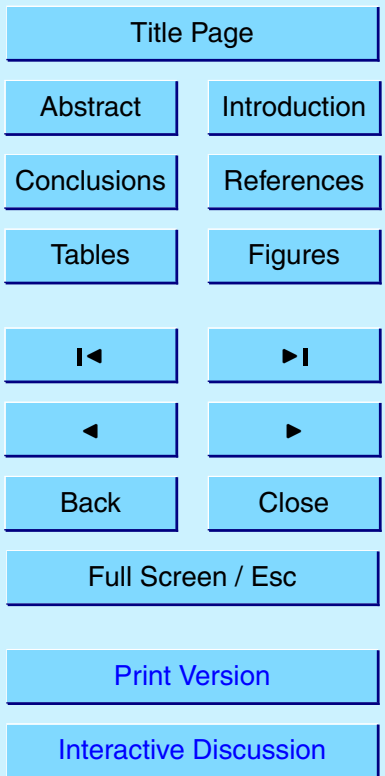

Fig. 3. Hourly average temporal trends of Mg-rich particles $(\mathrm{Mg})$ with pure sea salt particles $\left(\mathrm{NaCl}_{\mathrm{x}}\right)$. The correlation between the two types of particles is $\mathrm{R}^{2}=0.8$. 


\section{ACPD}

$5,10799-10838,2005$
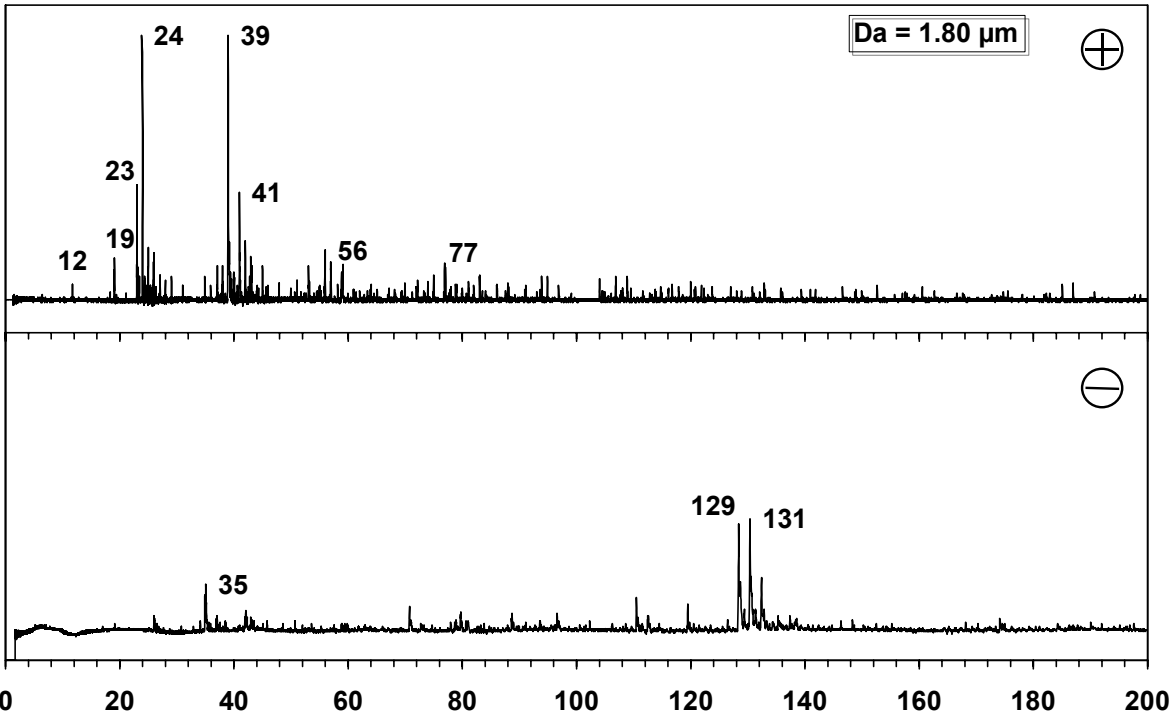

Studies of aerosol using two aerosol mass spectrometers

M. Dall'Osto et al.

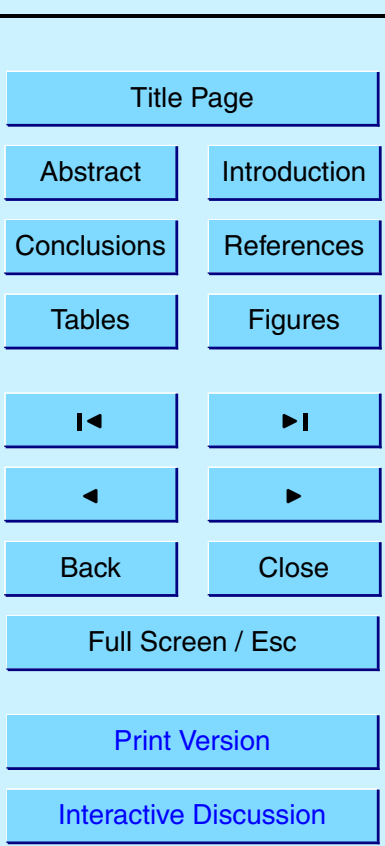

Fig. 4. Aerosol time-of-flight mass spectrometry (ATOFMS) single-particle positive (plus) and negative (minus) ion mass spectra of a particle attributed to Mg-rich particles (cluster 1E). 


\section{ACPD}

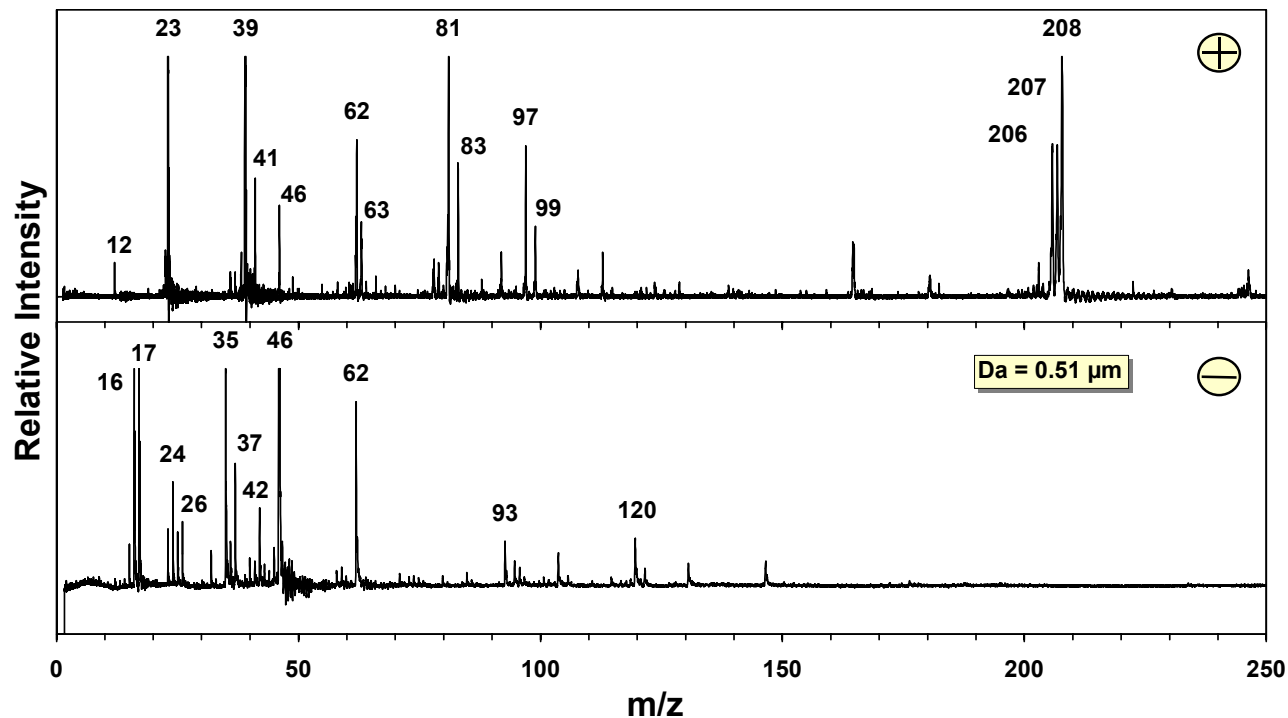

Fig. 5. Single particle positive (plus) and negative (minus) ion mass spectra of a particle of $1.06 \mu \mathrm{m}$ detected during a polluted event.
5, 10799-10838, 2005

\section{Studies of aerosol using two aerosol mass spectrometers}

M. Dall'Osto et al.

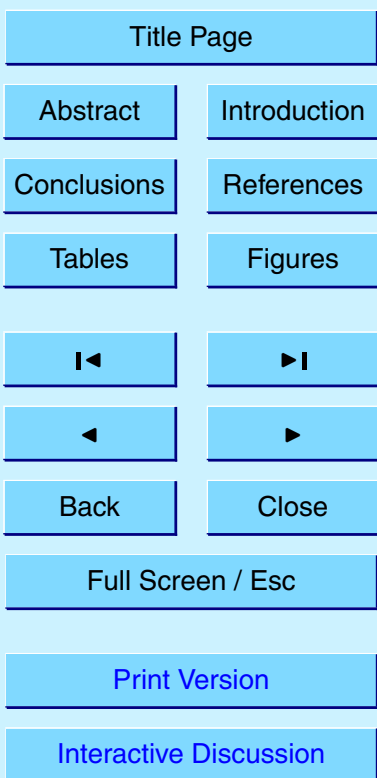

EGU 


\section{ACPD}

5, 10799-10838, 2005

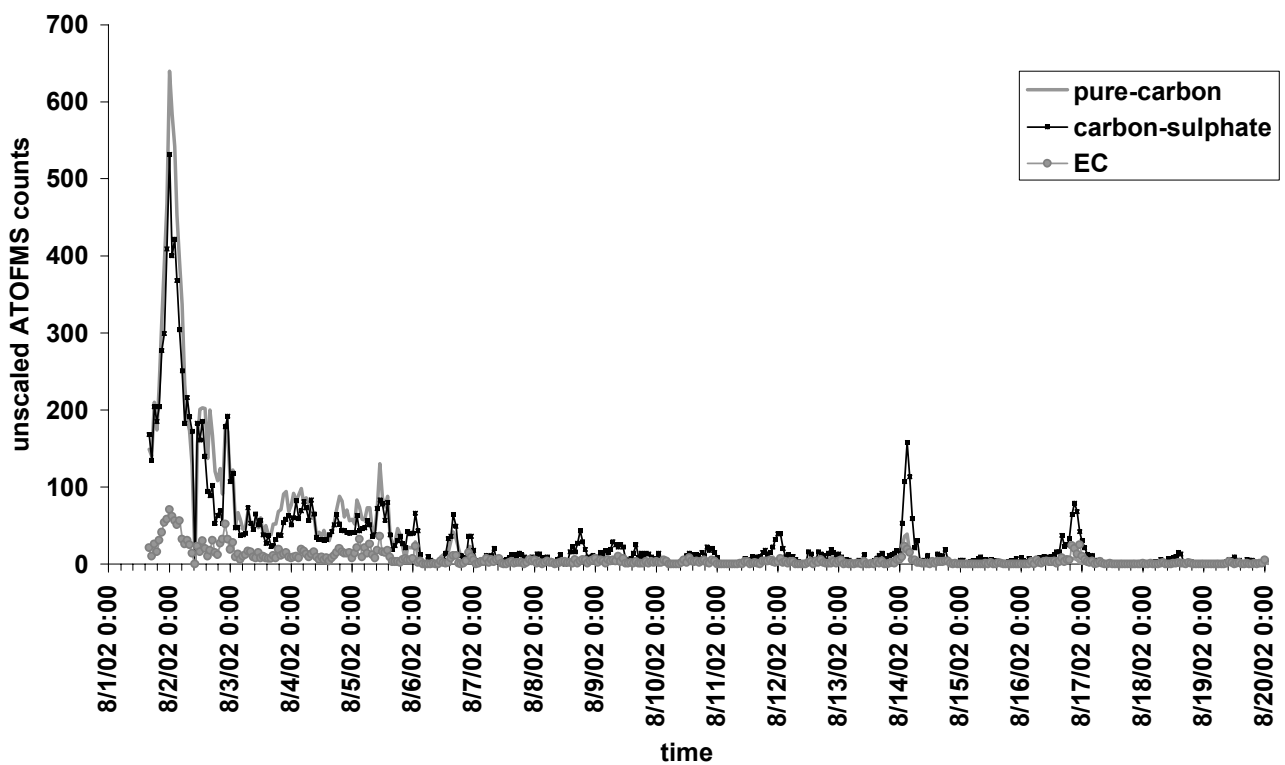

Studies of aerosol using two aerosol mass spectrometers

M. Dall'Osto et al.

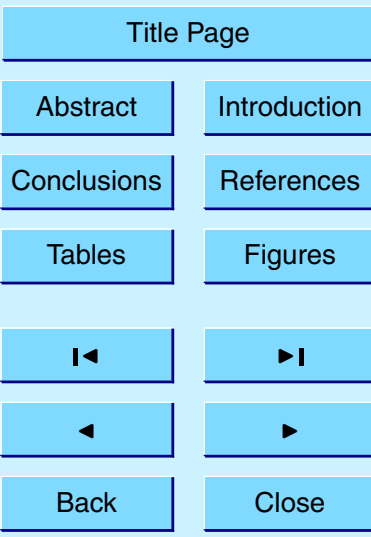

Fig. 6. ATOFMS hourly average temporal trends of pure carbon, carbon with sulphate and

Full Screen / Esc elemental carbon particles.

Print Version

Interactive Discussion

EGU 


\section{ACPD}

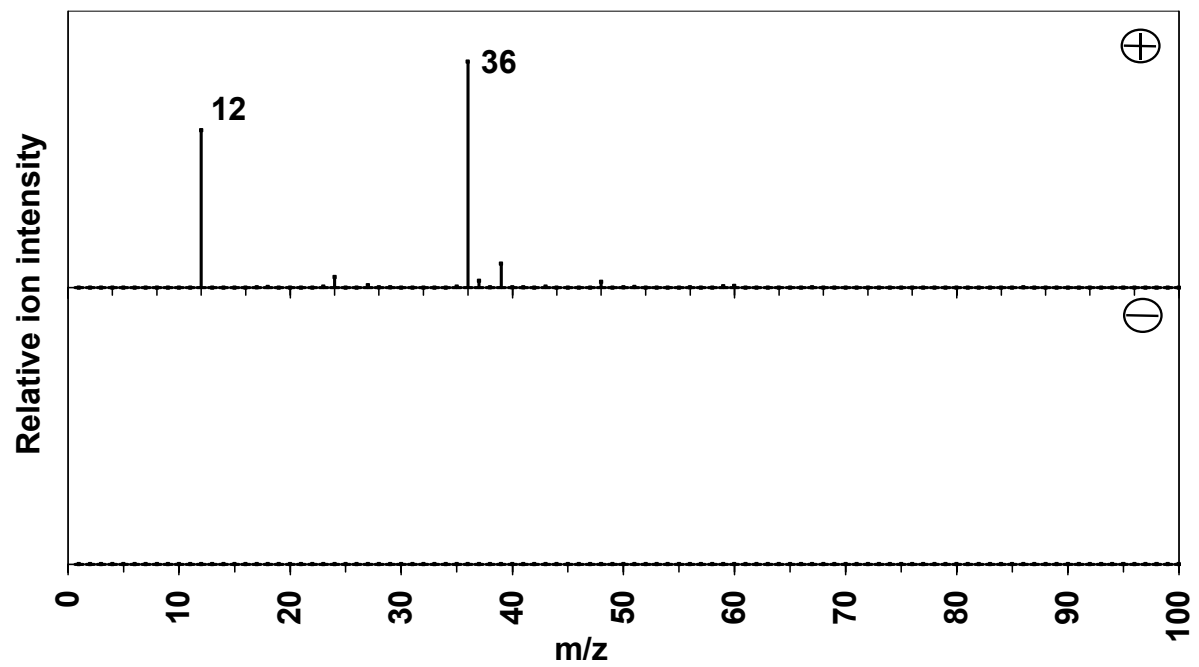

Fig. 7. ART-2a cluster (2A) positive (plus) and negative (minus) mass spectra of particles attributed to carbon-only cluster.
5, 10799-10838, 2005

\section{Studies of aerosol using two aerosol mass spectrometers}

M. Dall'Osto et al.

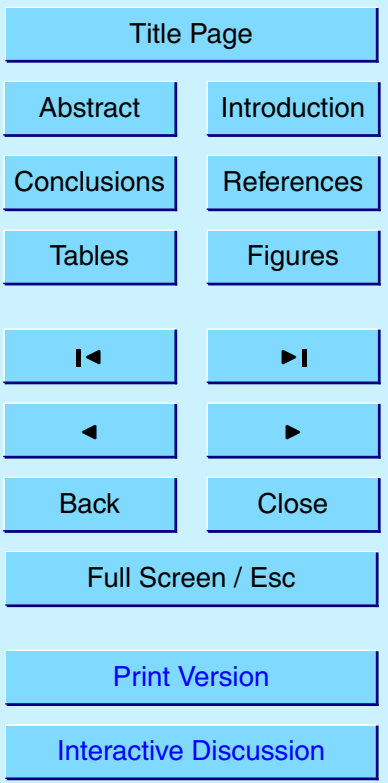

EGU 


\section{ACPD}

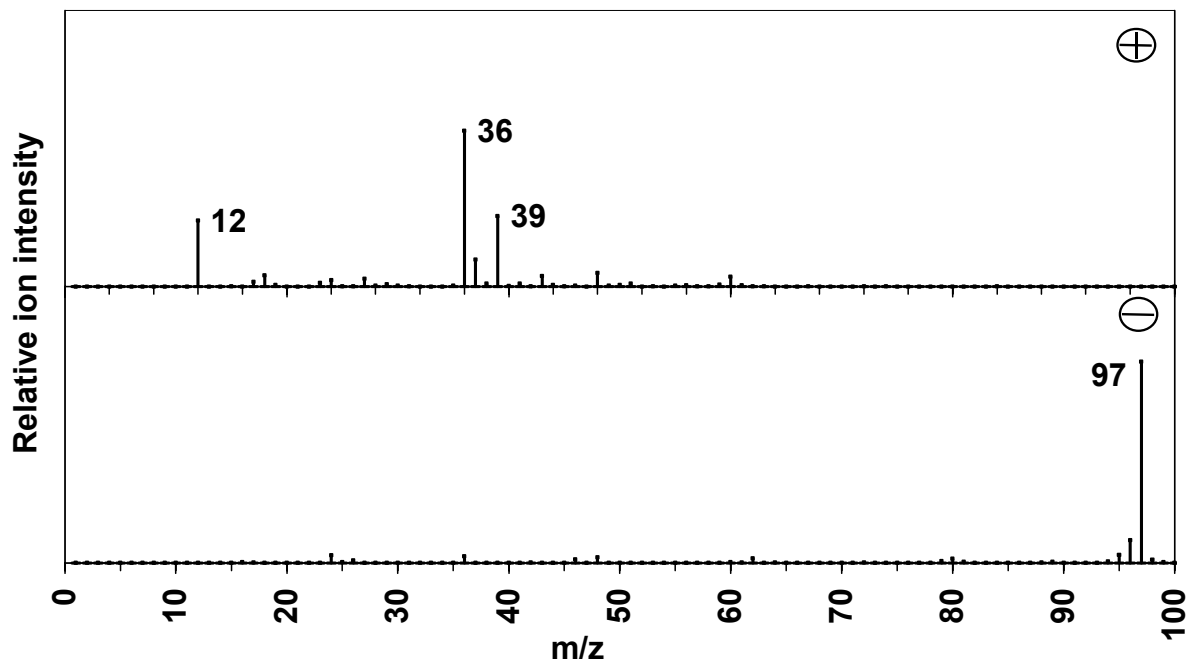

5, 10799-10838, 2005

\section{Studies of aerosol using two aerosol mass spectrometers}

M. Dall'Osto et al.

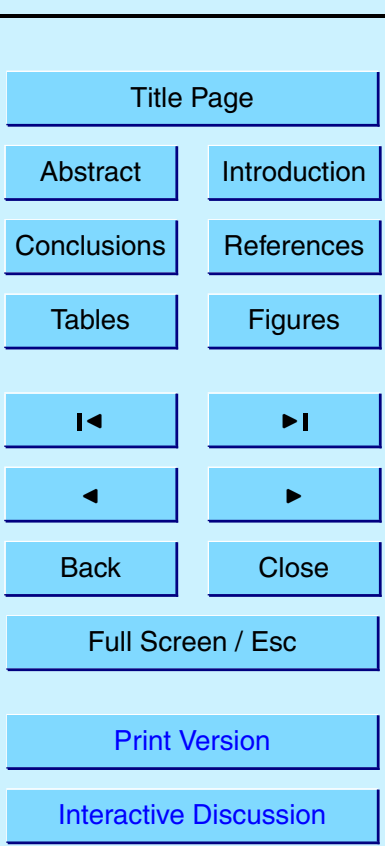

Fig. 8. ART-2a cluster (2B) positive (plus) and negative (minus) mass spectra of particles attributed to carbon-sulphate cluster. 


\section{ACPD}

5, 10799-10838, 2005

\section{Studies of aerosol using two aerosol mass spectrometers}

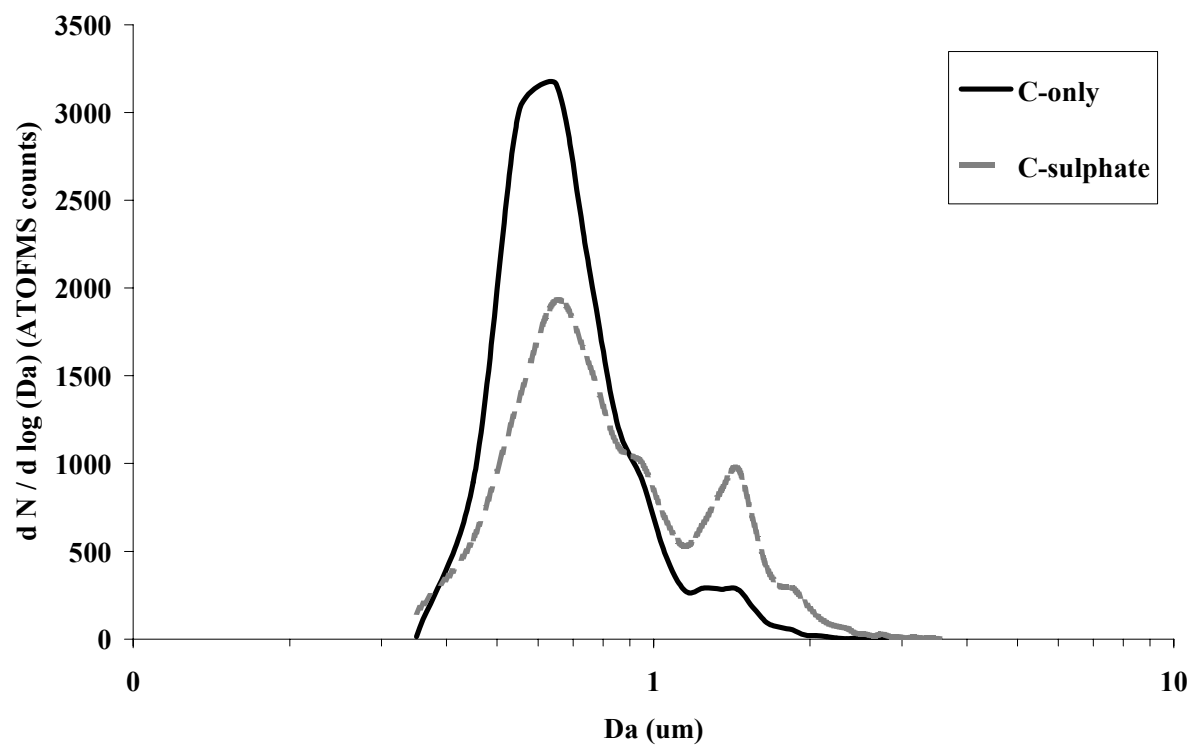

M. Dall'Osto et al.

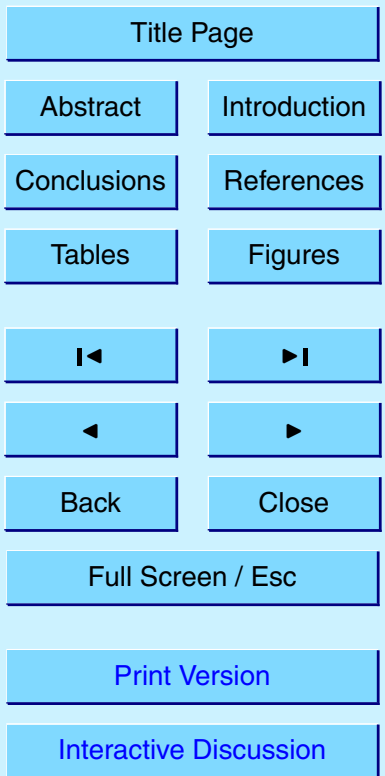

Fig. 9. ATOFMS size distribution of clusters $2 \mathrm{~A}$ (carbon-only) and $2 \mathrm{~B}$ (carbon-sulphate) containing particles. 


\section{ACPD}

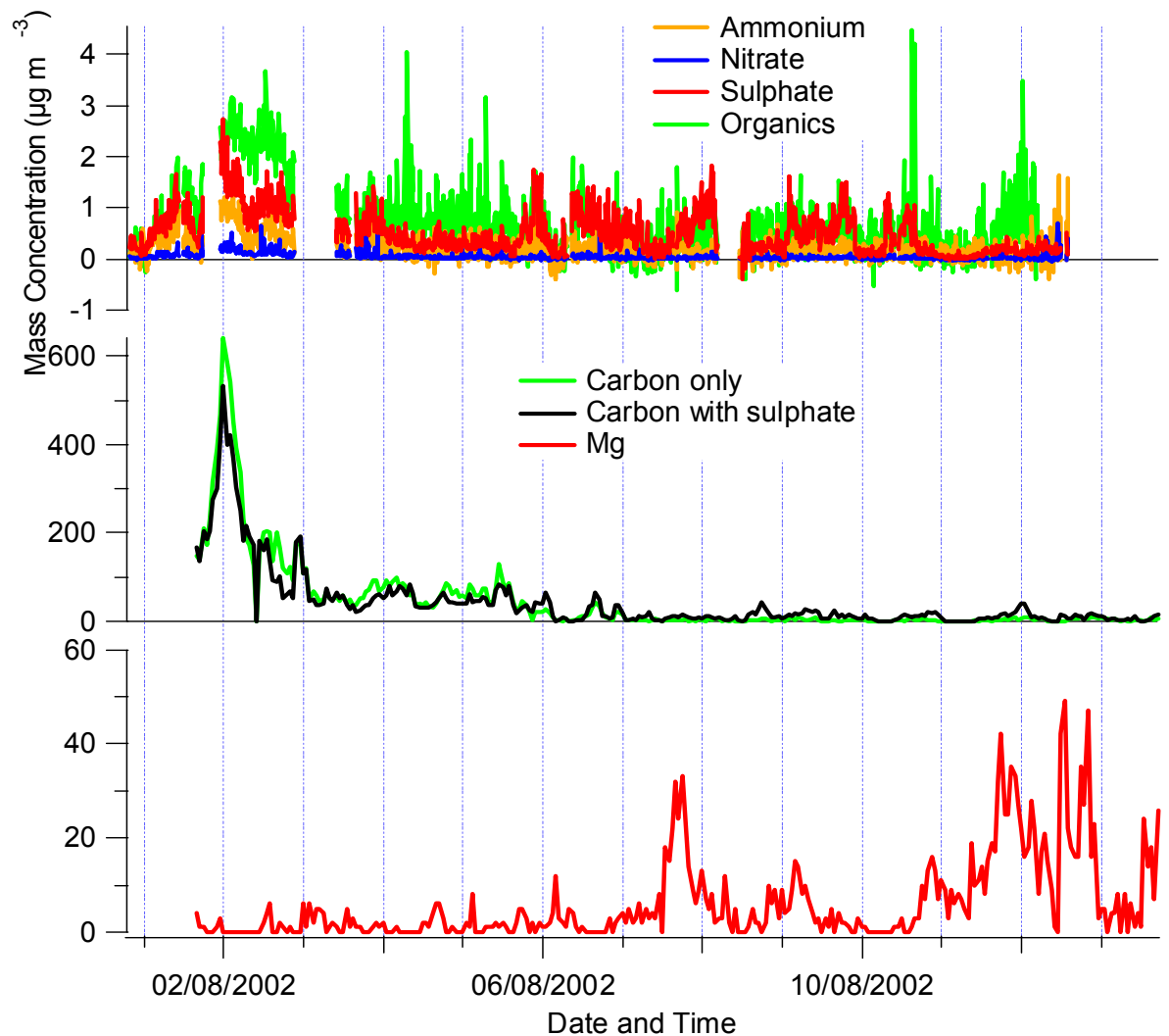

Fig. 10. AMS mass loading $\left(\mu \mathrm{g}^{*} \mathrm{~m}^{-3}\right)$ and ATOFMS hourly counts (ART-2a classes) for the whole period in which both mass spectrometers were operating.
5, 10799-10838, 2005

\section{Studies of aerosol using two aerosol mass spectrometers}

M. Dall'Osto et al.

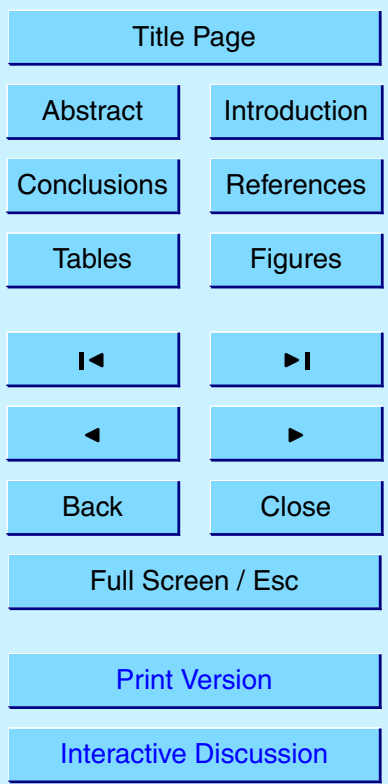

EGU 


\section{ACPD}

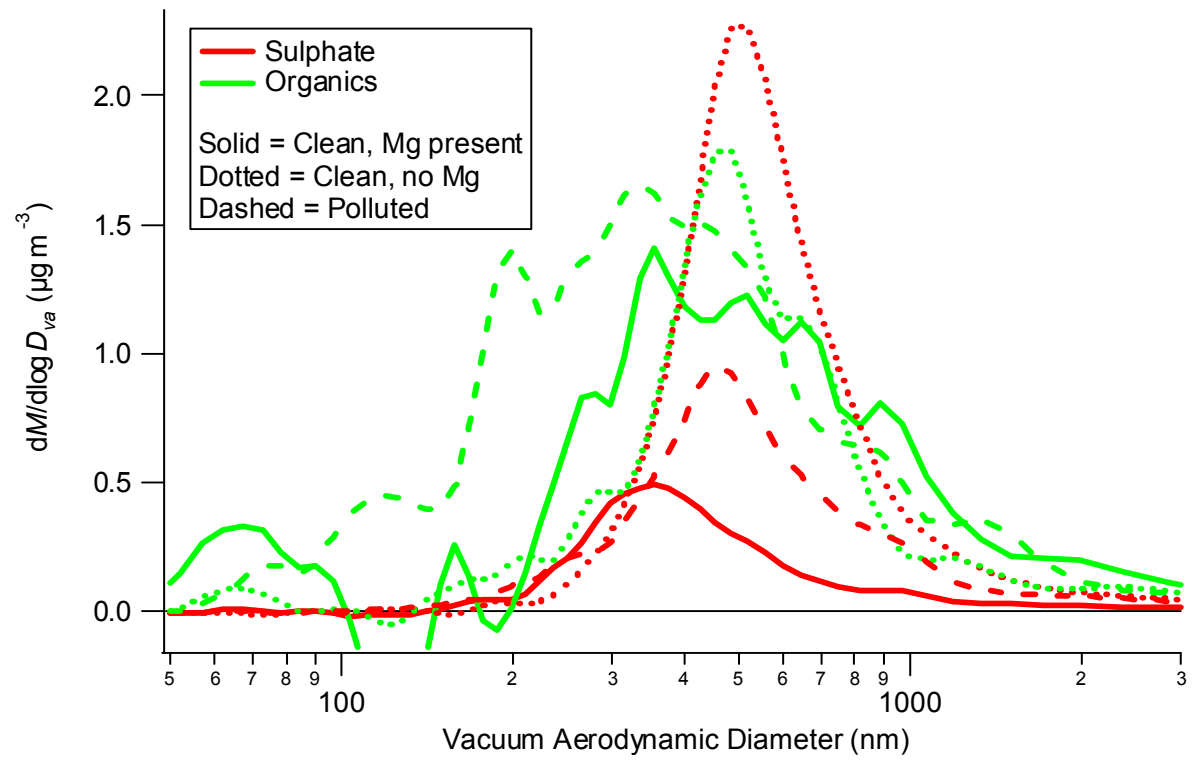

Fig. 11. Comparison of the mass distribution of sulphate and organics detected during periods of different meteorological conditions in Mace Head for August 2002. In the coarse mode $(>700 \mathrm{~nm})$, there is a major difference in the organic behaviour compared to the sulphate.
5, 10799-10838, 2005

\section{Studies of aerosol \\ using two aerosol mass spectrometers}

M. Dall'Osto et al.

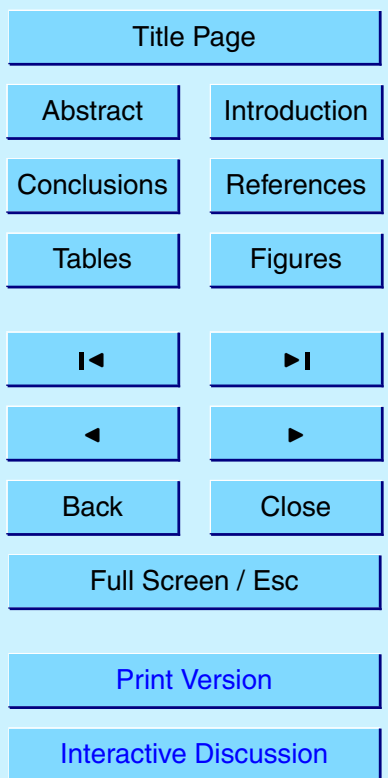




\section{ACPD}

5, 10799-10838, 2005

\section{Studies of aerosol using two aerosol mass spectrometers}

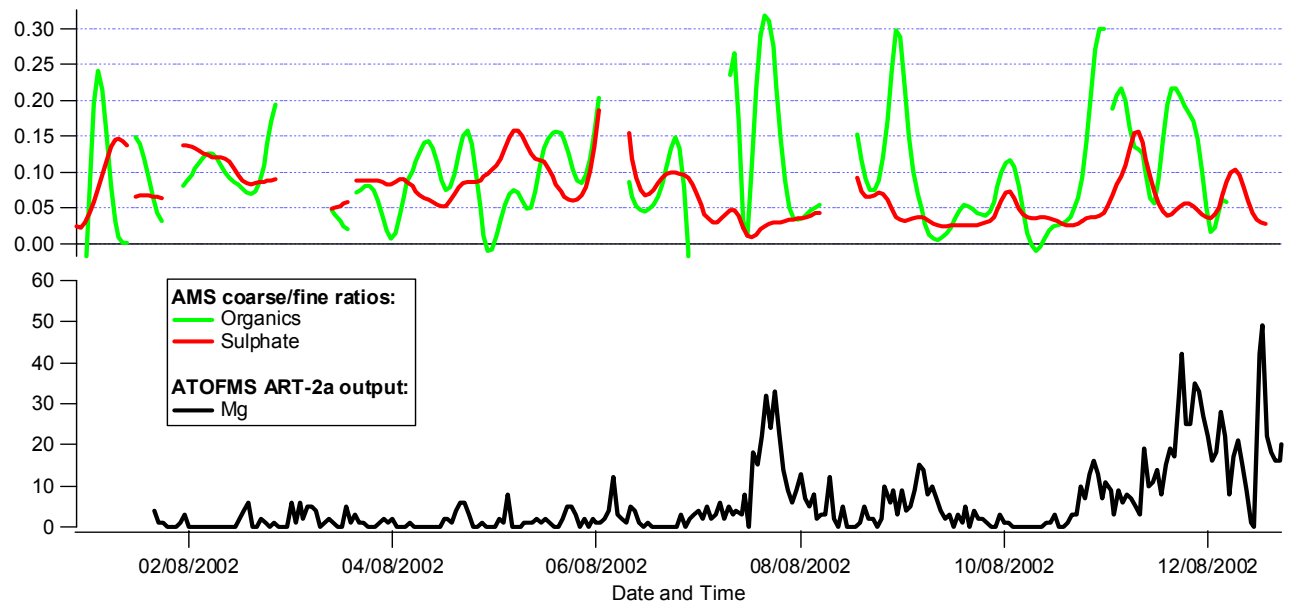

M. Dall'Osto et al.

Fig. 12. Coarse/fine ratio for organic and sulphate detected with AMS along with hourly averaged Mg-rich particles detected with ATOFMS.

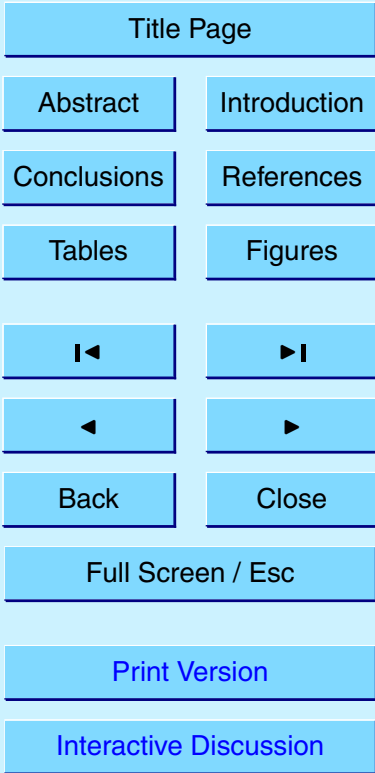

EGU 


\section{ACPD}

5, 10799-10838, 2005

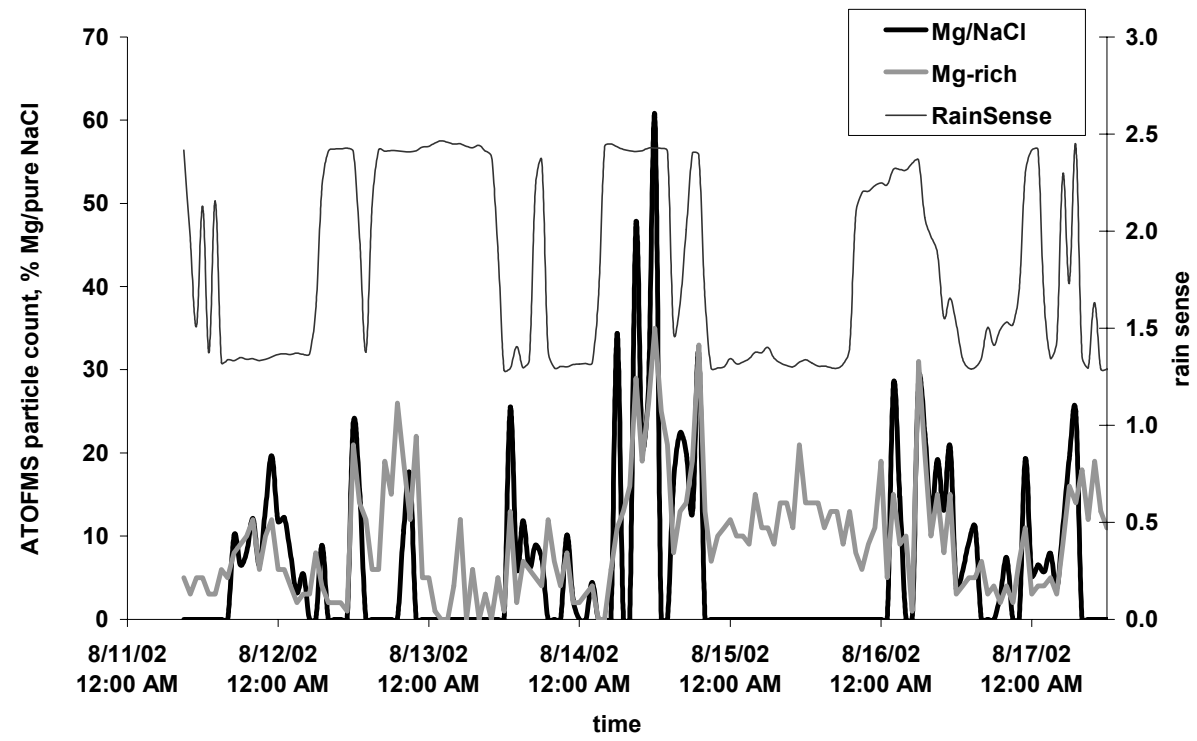

Studies of aerosol using two aerosol mass spectrometers

M. Dall'Osto et al.

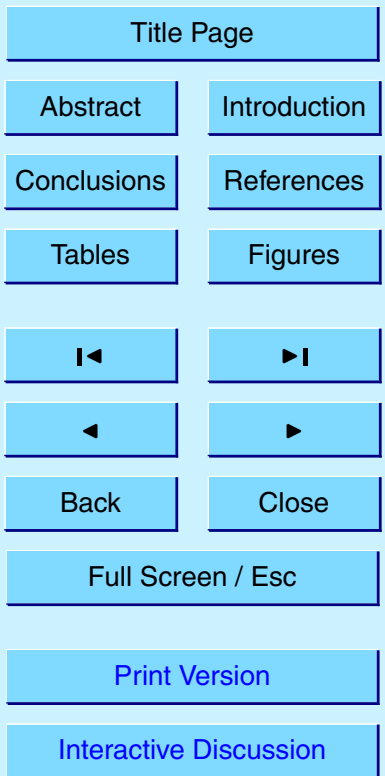

Fig. 13. Mg-rich particles to pure sea salt particles ratio. The fraction of Mg-rich particles is higher during periods of heavy rain. Only ATOFMS hourly bins with at least $10 \mathrm{Mg}$-particles were considered. 